\title{
Antiviral Activity of Approved Antibacterial, Antifungal, Antiprotozoal and Anthelmintic Drugs: Chances for Drug Repurposing for Antiviral Drug Discovery
}

\author{
Leena Abdulaziz', Esraa Elhadi ${ }^{1,2}$, Ejlal A Abdallah ${ }^{3}$, Fadlalbaseer A Alnoor ${ }^{4}$, Bashir A Yousef $\mathbb{D}^{5}$ \\ 'Department of Pharmacology, Faculty of Pharmacy, Omdurman Islamic University, Khartoum, I44I5, Sudan; ${ }^{2}$ Jiangsu Key Laboratory of Drug \\ Screening, China Pharmaceutical University, Nanjing, 210009, People's Republic of China; ${ }^{3}$ Department of Pharmacology and Pharmacy Practice, \\ Faculty of Pharmacy, Sudan University of Science and Technology, Khartoum, I I I I, Sudan; ${ }^{4}$ Department of Pharmacology, Faculty of Pharmacy, \\ National University, Khartoum, I I I I, Sudan; ${ }^{5}$ Department of Pharmacology, Faculty of Pharmacy, University of Khartoum, Khartoum, I I I I, Sudan
}

Correspondence: Bashir A Yousef, Department of Pharmacology, Faculty of Pharmacy, University of Khartoum, Al-Qasr Ave, Khartoum, IIIII, Sudan, Tel +249 9129324 I8, Fax +249 183780696, Email bashiralsiddiq@gmail.com

\begin{abstract}
Drug repurposing process aims to identify new uses for the existing drugs to overcome traditional de novo drug discovery and development challenges. At the same time, as viral infections became a serious threat to humans and the viral organism itself has a high ability to mutate genetically, and due to serious adverse effects that result from antiviral drugs, there are crucial needs for the discovery of new antiviral drugs, and to identify new antiviral effects for the exciting approved drugs towards different types of viral infections depending on the observed antiviral activity in preclinical studies or clinical findings is one of the approaches to counter the viral infections problems. This narrative review article summarized mainly the published preclinical studies that evaluated the antiviral activity of drugs that are approved and used mainly as antibacterial, antifungal, antiprotozoal, and anthelmintic drugs, and the preclinical studies included the in silico, in vitro, and in vivo findings, additionally some clinical observations were also included while trying to relate them to the preclinical findings. Finally, the structure used for writing about the antiviral activity of the drugs was according to the families of the viruses used in the studies to form a better image for the target of antiviral activity of different drugs in the different kinds of viruses and to relate between the antiviral activity of the drugs against different strains of viruses within the same viral family.
\end{abstract}

Keywords: drug repurposing, antiviral activity, antibacterial drugs, antifungal drugs, antiprotozoal agents, anthelmintic drugs

\section{Introduction}

Many viral infections are still causing remarkable threats to humans, such as HIV, coronavirus, SARS, avian influenza, swine flu, Dengue virus, Ebola virus, etc. ${ }^{1}$ Viruses are also able to emerge and re-emerge in human populations with changes in epidemiological characters that may occur gradually or abruptly as a result of sudden genetic changes during reproduction or replication. ${ }^{2}$ While the emergence of resistance to existing antiviral drugs and re-emerging viral infections are the biggest challenges in the antiviral drug discovery, drug repurposing, which is a process of identifying new uses for the existing drugs, is a promising, fast and cost-effective method that can overcome traditional de novo drug discovery and development challenges. The drug repurposing approach is an assuring strategy in finding new potential antiviral agents within a short time to overcome the challenges in antiviral therapy. ${ }^{3}$

Approved non-antiviral drugs that have demonstrated antiviral efficacy in vitro and animal studies are considered potential antivirals, especially during emergencies and during epidemics. ${ }^{4}$ Generally, the screening for drug repurposing takes two different experimental approaches, either to do phenotypic assay without knowing the target of the activity or to do a mechanism-based assay knowing the specific target of the antiviral effect, with the first approach being the most frequently applied. ${ }^{5}$ The targets for antiviral activity could also be either viral components or specific steps during viral 
infection related to the host cells, such as viral binding to host cells, viral entry into host cells, viral replication, and viral budding. $^{6}$

There are many approved non-antiviral drugs from different classes considered as candidate drugs for repurposing potential, including antibacterial and antiparasitic drugs. ${ }^{3}$ Although many researches were done to evaluate the antiviral activity of antibiotics, it was stated that caution should be considered when repurposing antibiotics for their antiviral effect, as the inappropriate use of the repurposed drugs could cause an increase in antimicrobial resistance. ${ }^{7}$ This review article focuses mainly on preclinical studies of phenotypic assays, and mechanism-based assays carried out to evaluate the antiviral activity of approved antibacterial, antifungal, antiprotozoal, and anthelmintic drugs, and some clinical findings related to it, and the summary of the antiviral effect of the drugs was according to the viral families and the viral species on which the antiviral study of the drug was done. Table 1 and Figure 1 demonstrate the possible mechanisms for the antiviral activity of approved antimicrobial agents.

Table I Possible Mechanism for Antiviral Activity of Approved Antibacterial, Antifungal, Antiprotozoal and Anthelmintic Agents

\begin{tabular}{|c|c|c|c|c|}
\hline Drug & Suggested Mechanism of Action & $\begin{array}{l}\text { Type of } \\
\text { Study }\end{array}$ & $\begin{array}{l}\text { Susceptible } \\
\text { Virus }\end{array}$ & References \\
\hline \multicolumn{5}{|c|}{ I. Antibacterial drugs } \\
\hline \multicolumn{5}{|c|}{ I.I. Macrolides } \\
\hline Azithromycin & Blocking viral internalization into host cells during the early phase of infection & In vitro & $\begin{array}{l}\text { Influenza A virus } \\
(\mathrm{HINI})\end{array}$ & [67] \\
\hline Clarithromycin & $\begin{array}{l}\text { Inhibiting viral fusion with host cell, through reducing expression of isoform } A \text { of } \\
\text { the Rashomologus (Rho) family (RhoA). }\end{array}$ & In vitro & $\begin{array}{l}\text { Respiratory } \\
\text { syncytial virus }\end{array}$ & [162] \\
\hline \multirow[t]{2}{*}{ Erythromycin } & Reducing intercellular adhesion molecule I (ICAM-I) & In vitro & Rhinovirus & [86] \\
\hline & $\begin{array}{l}\text { Blocking rhinovirus-induced MUC5AC protein over production and blocking } \\
\text { rhinovirus-induced p } 44 / 42 \text { MAPK activation }\end{array}$ & In vitro & Rhinovirus & [87] \\
\hline \multirow[t]{2}{*}{ Fidaxomicin } & Inhibiting RNA-dependent RNA polymerase & In vitro & Zika virus & [21] \\
\hline & Inhibiting RNA-dependent RNA polymerase & In silico & SARS-CoV-2 & [57] \\
\hline \multicolumn{5}{|c|}{ 1.2. Quinolones } \\
\hline Moxifloxacin & Acting on viral main protease (Mpro) & In silico & SARS-CoV-2 & [58] \\
\hline Ofloxacin & Inhibiting large tumour antigen $(\mathrm{T} \mathrm{Ag})$ helicase activity & In vitro & Simian virus 40 & [144] \\
\hline \multirow[t]{2}{*}{ Levofloxacin } & $\begin{array}{l}\text { Reducing intercellular adhesion molecule I (ICAM-I) and the number of acidic } \\
\text { endosomes }\end{array}$ & In vitro & Rhinovirus & [88] \\
\hline & Inhibiting large tumour antigen ( $\mathrm{T} \mathrm{Ag}$ ) helicase activity & In vitro & $\mathrm{BK}$ virus & [147] \\
\hline \multirow[t]{3}{*}{ Ciprofloxacin } & Decreasing large tumour antigen ( $\mathrm{T} \mathrm{Ag}$ ) expression & In vitro & $\mathrm{BK}$ virus & {$[141]$} \\
\hline & Inhibiting large tumour antigen $(\mathrm{T} \mathrm{Ag})$ helicase activity & In vitro & Simian virus 40 & [144] \\
\hline & Acting on viral main protease (Mpro) & In silico & SARS-CoV-2 & [58] \\
\hline \multicolumn{5}{|c|}{ I.3. Tetracyclines } \\
\hline \multirow[t]{4}{*}{ Doxycycline } & $\begin{array}{l}\text { Interfering with the interactions between the E protein and the host surface } \\
\text { receptor (inhibit viral entry). }\end{array}$ & In silico & Dengue virus & [27] \\
\hline & Inhibiting viral serine protease. & In vitro & Dengue virus & [28] \\
\hline & Disrupting the interactions between virus RNA and nucleoprotein. & In silico & $\mathrm{CCHFV}$ & [166] \\
\hline & Interfering with viral cysteine protease and E2 envelope glycoprotein & In silico & CHIKV & {$[|3|]$} \\
\hline
\end{tabular}


Table I (Continued).

\begin{tabular}{|c|c|c|c|c|}
\hline Drug & Suggested Mechanism of Action & $\begin{array}{l}\text { Type of } \\
\text { Study }\end{array}$ & $\begin{array}{l}\text { Susceptible } \\
\text { Virus }\end{array}$ & References \\
\hline Lymecycline & Interfering with 3-chymotrypsin-like protease (3CLpro) and helicase (Nsp/3) & In silico & SARS-CoV & [5। $]$ \\
\hline Oxytetracycline & Interfering with 3-chymotrypsin-like protease (3CLpro) & In silico & SARS-CoV & [5। $]$ \\
\hline Tigecycline & Interfering with papain-like protease (PLpro) & In silico & SARS-CoV & [5। $]$ \\
\hline Minocycline & Reducing level of apoptosis signal-regulating kinase I (ASKI) & In vitro & HIV and SIV & {$[100]$} \\
\hline \multicolumn{5}{|c|}{ 1.4. Other antibacterial drugs } \\
\hline Rifampicin & Acting on viral Main Protease (Mpro) & In silico & SARS-CoV-2 & [60] \\
\hline Cycloserine & Reducing syncytium formation and p24 protein production & In vitro & HIV-I & [119] \\
\hline Fusidic acid & Reducing syncytium formation and inhibit reverse transcriptase & In vitro & HIV-I & {$[114,116]$} \\
\hline Chloramphenicol & Interfering with papain-like protease (PLpro) & In silico & SARS-CoV & [5। $]$ \\
\hline \multicolumn{5}{|l|}{ 2. Antifungal drugs } \\
\hline Amphotericin B & Impairing the attachment and internalization of the virus by host cells. & In vitro & Enterovirus 7I & [96] \\
\hline Posaconazole & $\begin{array}{l}\text { Affecting intracellular cholesterol distribution by targeting oxysterol-binding } \\
\text { protein }\end{array}$ & In vitro & Dengue virus & [39] \\
\hline \multirow[t]{2}{*}{ Itraconazole } & Suppressing viral RNA replication or polyprotein processing & In vitro & Enterovirus 71 & [93] \\
\hline & $\begin{array}{l}\text { Affecting intracellular cholesterol distribution by targeting oxysterol-binding } \\
\text { protein }\end{array}$ & In vitro & Dengue virus & [39] \\
\hline \multirow[t]{2}{*}{ Caspofungin } & Acting on viral main protease (Mpro) & In silico & $\begin{array}{l}\text { SARS-CoV and } \\
\text { SARS-CoV-2 }\end{array}$ & [63] \\
\hline & Acting on viral nonstructural protein 12 & In vitro & SARS-CoV-2 & [64] \\
\hline \multicolumn{5}{|c|}{ 3. Antiprotozoal agents } \\
\hline \multirow[t]{3}{*}{ Quinine } & Indirectly by inducing host cell defense mechanisms & In vitro & HSV-I & {$[16]$} \\
\hline & Interfering with terminal glycosylation in Golgi apparatus. & In vitro & HIV-I & {$[120,123]$} \\
\hline & $\begin{array}{l}\text { Inhibiting the post-translational modification of glycoprotein } 120 \text { by increasing } \\
\text { endosomal } \mathrm{pH}\end{array}$ & In vitro & HIV-I & [129] \\
\hline Hydroxychloroquine & $\begin{array}{l}\text { Inhibiting the post-translational modification of glycoprotein } 120 \text { by increasing } \\
\text { endosomal } \mathrm{pH}\end{array}$ & In vitro & HIV-I & {$[120]$} \\
\hline Atovaquone & Acting on viral main protease (Mpro) & In silico & SARS-CoV-2 & [66] \\
\hline \multicolumn{5}{|c|}{ 4. Antihelminthic drugs } \\
\hline Mebendazole & Acting on viral main protease (Mpro) & In silico & SARS-CoV-2 & [66] \\
\hline
\end{tabular}

Abbreviations: SARS-CoV, severe acute respiratory syndrome coronavirus; CCHFV, Crimean-Congo hemorrhagic fever virus; CHIKV, chikungunya virus; HIV, human immunodeficiency virus; SIV, simian immunodeficiency virus.

\section{Drugs Acting on Herpesviridae Viruses}

A few drugs belonging to the antimicrobial chemotherapeutic category showed the ability to affect viruses of the herpesviridae family as documented in previous researches, namely neomycin and doxycycline as antibacterial agents, posaconazole and ketoconazole as antifungal agents, and quinine as antiprotozoal. 


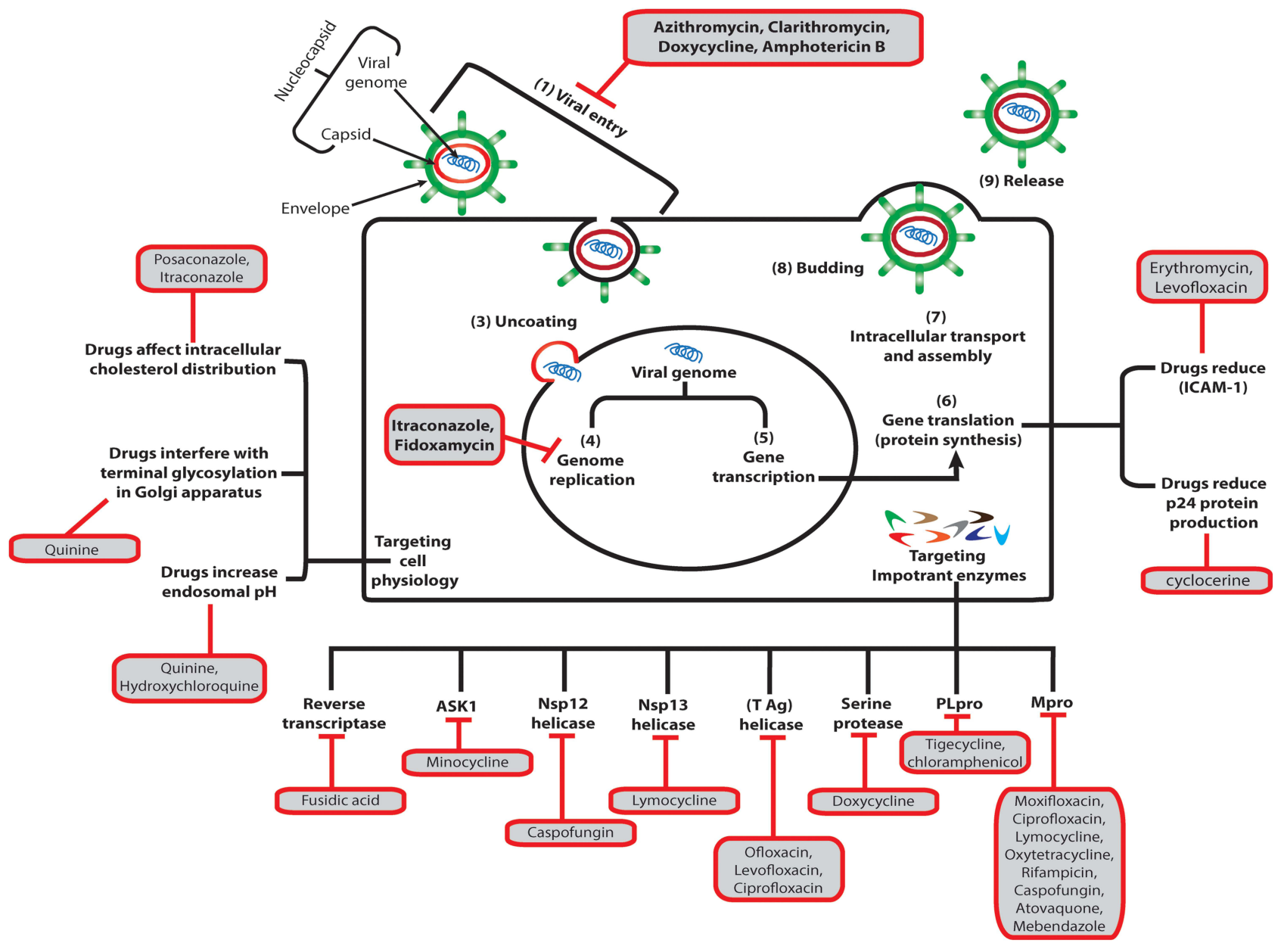

Figure I Suggested stages of viral infection at which approved antimicrobial agents exert their antiviral effect.

Neomycin, an antibacterial drug showed ability to inhibit herpes simplex virus type 1 (HSV-1) proliferation in vitro by interfering with very early stages of HSV 1 infection with an effect strongly dependent on the time of adding the drug in contrast with the time of infection. Moreover, the effect was suggested to be highly specific since the drug almost completely inhibited HSV-1 infection but did not affect HSV-2 infection. ${ }^{8,9}$ Further studies proved that the presence of neomycin in the infected tissue at the time of infection almost completely blocked HSV-1 infection, while the addition of the drug later does not affect the normal course of infection; also regarding its mechanism of anti-HSV-1 action evidence suggests that neomycin exerts its effect by specifically inhibiting HSV-1 receptor binding. ${ }^{10}$ This was further proved by another study that documented that neomycin exerts its effect by two mechanisms: firstly by partial inhibition of the glycoprotein-C dependent binding of the virions, and secondly by inhibition of events that occur after binding the virus to cells. ${ }^{11}$ Another effective drug is doxycycline, which was documented that when combined in low-dose with monocaprin, it offers an effective treatment for herpes labialis, significantly reducing time to healing and pain. ${ }^{12}$ Moreover, it was proved that topical application of neomycin in an in vivo model resulted in enhanced expression of antiviral interferonstimulated genes (ISGs) associated with a reduction in HSV-2 infection. ${ }^{13}$

Two antifungal drugs, posaconazole and ketoconazole showed activity against some strains of herpesviridae. Posaconazole showed broad anti-human cytomegalovirus (HCMV) activities, even against strains resistant to viral DNA polymerase inhibitor drugs. It was also observed that posaconazole increased the anti-HCMV activity of ganciclovir to tenfold its activity, indicating that posaconazole act synergistically with ganciclovir in inhibiting HCMV 
replication. ${ }^{14}$ On the other hand, ketoconazole showed activity against herpes simplex virus (HSV), as treatment of human lung cells infected with HSV-1 and -2 with ketoconazole resulted in a dose-dependent reduction in viral titer. ${ }^{15}$

Quinine, an antimalarial drug, also showed in vitro activity against HSV-1, as demonstrated by a decrease in virus plaques. It was suggested that the quinine exerts its antiviral effect by acting indirectly on the host cells by inducing a cellular defense mechanism that can interfere with multiple events during the virus replication cycle, besides nuclear factor kappa-B (NF-kB) inhibition induced by quinine blocks the gene expression and causes a considerable reduction in the viral infection. It was stated that this indirect mode of action by affecting host cells decreases the chance of viruses becoming resistant to the drug. ${ }^{16}$

\section{Drugs Acting on Flaviviridae Viruses}

Some drugs belonging to the macrolides, tetracyclines, quinolones, aminoglycosides, and cyclic lipopeptide antibiotics, in addition to some antimalarial and antifungal drugs showed ability to inhibit some Flaviviridae viruses.

Three members of the macrolide antibiotics showed activity against some Flaviviridae viruses. One of them is erythromycin which demonstrated activity against zika virus (ZIKV) both in vitro and in vivo more over the drug was able to protect against vertical transmission of ZIKV in pregnant mice, additionally to be able to inhibit dengue virus (DENV) and yellow fever virus (YFV). In terms of the mechanism of action by which erythromycin affects ZIKV, the drug inhibits viral entry by disrupting viral membrane integrity, resulting in loss of viral infectivity. ${ }^{17}$ Azithromycin, which is another macrolide antibiotic, was also able to inhibit replication of ZIKV in different in vitro models, ${ }^{18,19}$ in addition to its ability to inhibit ZIKV infection in vivo as shown in a study that documented that azithromycin was able to prevent zika virus-induced lethality in the suckling mouse model. ${ }^{20}$ Fidaxomicin also showed potential inhibitory interaction with RNA-dependent RNA polymerase (RdRp) of ZIKV in an in silico model, suggesting its probability of acting as a potential RdRp inhibitor. ${ }^{21}$

Regarding the effect of tetracycline antibiotics on Flaviviridae viruses, two drugs of this class (demeclocycline and minocycline) showed activity against the West Nile virus (WNV) in vitro, with further investigation in the activity of minocycline showing that additionally to reducing WNV titer in tested cell lines the drug was also able to inhibit WNV induced apoptosis and suppress virus-induced activation of c-Jun N-terminal kinase (JNK) and its target c-Jun. ${ }^{22}$ It was also documented that the anti-inflammatory environment induced by minocycline reduced viral cytotoxicity during WNV infection in ex vivo central nervous system (CNS) tissue. ${ }^{23}$ Japanese encephalitis virus (JEV) was also affected by minocycline as the drug showed protective effects in mice infected with JEV demonstrated by a reduction in neuronal apoptosis, microglial activation, active caspase activity, pro-inflammatory mediators, and viral titer. ${ }^{24}$ Additionally, it was documented that minocycline inhibited the reactive oxygen species (ROS) production associated with JEV infection. ${ }^{25}$ The spectrum of tetracycline antibiotics against the Flaviviridae viruses also included the DENV as minocycline affected the DENV infection at different stages, such as viral RNA synthesis and intracellular envelope protein expression. Minocycline also modulated host factors, including the phosphorylation of extracellular signal-regulated kinase $1 / 2$ $\left(\right.$ ERK1/2). ${ }^{26}$ On the other hand, doxycycline demonstrated in vitro inhibitory effects against DENV propagation. Also, the in silico findings showed its ability to interact with critical residues that affect membrane fusion during viral entry. ${ }^{26}$ In vitro studies also documented that doxycycline could inhibit the DENV serine protease (DENV2 NS2B-NS3pro), and its ability to decrease the virus titter significantly inhibited viral entry and reduce post-infection viral replication. ${ }^{27}$

Other antibacterial agents also showed antiviral activity against some Flaviviridae viruses, such as ofloxacin, a fluoroquinolone antibiotic effect on hepatitis $\mathrm{C}$ virus (HCV), as Ofloxacin was remarkably effective in inhibiting $\mathrm{HCV}$ RNA in Huh-7 cells infection in vitro model. ${ }^{28}$ Moreover, previous clinical results suggested that combination therapy of IFN and ofloxacin may be effective for hepatitis $\mathrm{C}$ management. ${ }^{29-31}$ However, some other findings indicated that the combined administration of $\alpha$-interferon and ofloxacin to patients with chronic hepatitis $\mathrm{C}$ who have not responded to $\alpha$-interferon alone does not increase the primary virological response rate. ${ }^{32}$ Another drug with an unconfirmed antiviral effect is daptomycin, a cyclic lipopeptide antibiotic, as some findings documented that daptomycin could be identified as an inhibitor of ZIKV infection in vitro activity against ZIKV strain. ${ }^{33}$ Other findings stated that treatment with daptomycin was insufficient to lower the percentage of infected cells in vitro below $46 \%$ even at the highest dose in the tested cell type. ${ }^{19}$ Furthermore, neomycin, an aminoglycoside antibiotic, showed the ability to enhance the expression 
of antiviral interferon-stimulated genes (ISGs) associated with a reduction in ZIKV RNA level after topical application in an in vivo animal model. ${ }^{13}$

The inhibitory effect against Flaviviridae viruses was also detected with some antifungal drugs, as an example amphotericin B inhibited the replication of JEV with the reduction in both plaque size and number of the infected cells in a dose-dependent manner. It was indicated that the drug acts at the post-virus-infection step, but not during adsorption of virus to host cells. ${ }^{34}$ Amphotericin B also causes significant ultrastructural and biochemical changes in hepatitis B virus (HBV) particles, and hepatitis B surface antigen (HBsAg) particles disruption into a nonparticulate HBsAg-reactive fraction and a HBsAg-AmB complex fraction with no HBsAg immunoreactivity. ${ }^{35}$ The effect of amphotericin B on HBV was also observed in another study, as it stated that amphotericin B and ketoconazole exhibited a dose-dependent decrease in the production of HBsAg particles by the human hepatoma cell line in vitro paralleled by a reduction in cellular protein synthesis. ${ }^{36} \mathrm{HCV}$ was also subjected to inhibition by an antifungal drug, as a previous study documented that the replication of a subgenomic hepatitis $\mathrm{C}$ virus genotype $1 \mathrm{~b}(\mathrm{HCV}-1 \mathrm{~b})$ replicon can be suppressed by griseofulvin. It decreased the replicon RNA titer in Huh7/Rep-Feo cells in vitro in a dose-dependent manner, and it was proved that griseofulvin induces G2/M cell cycle arrest in HCV replicon cells. Moreover, it was found that the effect of the griseofulvin and IFN $\alpha$ combination on HCV-RNA replication is strongly synergistic. ${ }^{37}$ Lastly, posaconazole was able to inhibit replication of multiple serotypes of DENV and ZIKV, and reduced viral RNA replication, but not translation of the viral genome, with a suggestion that oxysterol-binding protein (OSBP) mediates the antiviral activity of posaconazole. $^{38}$

Some antimalarial drugs also showed activity against some Flaviviridae viruses, such as mefloquine which showed activity against $\mathrm{DENV}^{39}$ and $\mathrm{ZIKV}{ }^{33,39}$ Chloroquine also showed activity against $\mathrm{DENV}^{40-42}$ and $\mathrm{ZIKV}{ }^{43,44}$ in addition to its activity against $\mathrm{HCV}$ as demonstrated by in vitro experiments that screened the antiviral activity of chloroquine and hydroxychloroquine against HCV in Huh-5-2 cells, in which both drugs were able to reduce the HCV-RNA. ${ }^{45}$ The additional finding confirmed this inhibitory effect of chloroquine against $\mathrm{HCV}$, which stated that combining chloroquine with IFN $\alpha$ exerts a synergistic effect against $\mathrm{HCV}^{46}$ Another antimalarial drug that showed antiviral activity is atovaquone, which showed antiviral activity against ZIKV and chikungunya virus in Vero cells at small concentrations. The observed antiviral effect was suggested to be via depletion of nucleotides blocking pyrimidine biosynthesis. ${ }^{47}$ Another study also confirmed this inhibitory effect of atovaquone on ZIKV and chikungunya virus virion production in human cells, and stated that the antiviral effect of the drug occurred early during infection at the initial steps of viral RNA replication. These findings were further proved using an ex vivo human placental tissue model in which atovaquone was able to limit ZIKV infection in a dose-dependent manner. ${ }^{48}$ Furthermore, quinine showed the ability to inhibit DENV replication in three different cell lines of human origin, this was associated with a reduction in viral RNA and viral protein synthesis in a dose-dependent manner, and it was suggested that quinine have the efficacy for stimulating antiviral genes to reduce DENV replication. ${ }^{49}$

\section{Drugs Acting on Coronaviridae Viruses}

Three tetracycline antibiotics showed effect on SARS-CoV-2 in an in silico target-based virtual ligand screening. It was documented that lymecycline and oxytetracycline showed high binding affinity to 3C-like protease (3CLpro). Lymecycline was also predicted to be helicase inhibitors, whereas tigecycline and chloramphenicol (another bacterial protein-synthesis inhibitor) showed high binding affinity to papain-like protease (PLpro).$^{50}$ There was an inconsistency in the clinical findings regarding macrolide antibiotics as a clinical trial study conducted on SARS-CoV-2 infected patients found that azithromycin added to hydroxychloroquine was significantly more efficient for virus elimination than hydroxychloroquine treatment as a single drug. ${ }^{51}$ In contrast, another study reported no benefit with the combination of hydroxychloroquine plus azithromycin at the same dose scheme reported in the previous study. ${ }^{52}$ Regardless of the clinical trial studies, the combination of hydroxychloroquine and azithromycin showed in vitro synergistic effect on SARS-CoV-2 at concentrations compatible with that obtained in the human lung. ${ }^{53}$ Besides, azithromycin by itself showed clear in vitro antiviral activity against SARS-CoV-2, ${ }^{54}$ also knowing that azithromycin is an acidotropic lipophilic weak base some studies were carried out on the drug itself to understand the mechanism of its antiviral effect on SARS-CoV-2. The results revealed that it could correct organellar $\mathrm{pH}$ in cystic fibrosis (CF) lung epithelial cells. It 
can also correct $\mathrm{CF}$ cell-autonomous innate immunity-related properties and responses, correct furin activity, and transform growth factor- $\beta$ (TGF- $\beta$ ) levels in CF cells. ${ }^{55}$

In silico studies also documented that fidaxomicin could be a potential inhibitor for RdRp, as it showed potential inhibitory interaction with RdRp of SARS-CoV-2. ${ }^{56}$ Quinolone antibiotics also demonstrated antiviral effect against Coronaviridae viruses as recently it was documented that ciprofloxacin acts as acidotropic lipophilic weak bases and shows in vitro effects on intracellular organelles. It showed the ability to correct the $\mathrm{pH}$ of acidified intracellular compartments in CF respiratory epithelial cells, indicating that the drug could act on the intracellular organelles $\mathrm{pH}$ in respiratory epithelial cells, a highly relevant target for SARS-CoV-2. ${ }^{55}$ Also, an in silico study showed that ciprofloxacin and moxifloxacin exert a strong capacity for binding to SARS-CoV-2 main protease (Mpro), as it binds to the protein active site more strongly than native ligand, suggesting that the drug may be a potential inhibitor of the tested protease. ${ }^{57}$ Additionally, clinical findings documented that treating SARS-CoV-2 infection with moxifloxacin and arbidol could help reduce viral load and inflammation during infection. ${ }^{58}$ Moreover, some antimycobacterial drugs also demonstrated activity against Coronaviridae viruses, such as rifampicin which appeared as a promising drug showing good binding energy to SARS-COV-2 Mpro in a molecular docking study, ${ }^{59}$ also clofazimine showed in vitro activity against the proliferation of feline infectious peritonitis (FIP) virus in Fcwf-4 cells, ${ }^{60}$ and in a study about the effect of clofazimine on SARS-CoV-2 infection the drug appeared to suppress isolated single infected cells (ROI 4), while a small number of syncytia (ROI 3) were still observable suggesting a replication inhibition. ${ }^{61}$

Antifungal drugs also showed antiviral activity against Coronaviridae viruses, as an in silico study stated that caspofungin is predicted to be a potential inhibitor against SARS-CoV Mpro and SARS-CoV-2 Mpro, and having an affinity for both viruses Mpro may indicate the potential of this drug as an inhibitor for other coronaviruses with similar Mpro binding sites and pocket structures. ${ }^{62}$ Also, caspofungin showed ability to bind with SARS-CoV-2 nsp12 protein and block the polymerase activity in vitro, and it was documented that the drug could effectively inhibit SARS-CoV-2 replication in vitro. ${ }^{63}$ Another drug is clioquinol which was identified as a potent inhibitor of SARS-CoV-2 infectioninduced cytopathic effect in vitro. In addition, all three compounds showed potent anti-exopeptidase activity against recombinant human angiotensin-converting enzyme 2 (rhACE2) and inhibited the binding of rhACE2 with SARS-CoV-2 Spike receptor-binding domain (RBD) protein, and it showed a strong correlation with inhibition of rhACE2 and rhACE2-RBD interaction. ${ }^{64}$

SARS-CoV-2 virus Mpro was also targeted by mebendazole, an anthelmintic drug, as an in silico study showed that mebendazole exhibited high binding affinity with mebendazole SARS-CoV-2 virus Mpro binding pocket, and it also showed activity against the virus in vitro in Vero E6 cells. ${ }^{65}$

\section{Drugs Acting on Orthomyxoviridae Viruses}

In vivo studies documented that neomycin significantly increases survival against influenza A virus A/PR8 (hvPR8) infection as observed in a respiratory tract infection model. ${ }^{13}$ Some members of the macrolide antibiotics also showed activity against influenza A virus, one of them is azithromycin which showed activity against the pandemic influenza 2009 (A(H1N1)pdm09) in vitro as the study showed that progeny virus replication was remarkably inhibited by treating viruses with azithromycin before infection; however, azithromycin administration after infection did not affect this process, and the mechanism of action was suggested to be by blocking viral internalization into host cells during the early phase of infection and targeting newly budded progeny virus from the host cells and inactivated their endocytic activity, while in vivo intranasal administration of azithromycin to influenza A (H1N1)pdm09 virus-infected mice successfully reduced viral load in the lungs and relieved infection-induced hypothermia. ${ }^{66}$ Also, clinical studies showed that combination therapy of oseltamivir with azithromycin demonstrated more efficacy in treating influenza A(H1N1) infected patients than using oseltamivir alone. ${ }^{67,68}$ Another macrolide antibiotic that showed activity against influenza A virus is clarithromycin which showed a significant inhibitory effect on influenza A virus infection in vitro; more specifically, the antiviral effect was detected when the infected cells were treated with clarithromycin after viral adsorption. Also, clarithromycin did not affect influenza virus hemagglutination, membrane fusion, and viral sialidase activities, which indicate that clarithromycin acts on the middle to late stage of the viral replication cycle resulting in inhibition of progeny virus production from the infected cells. ${ }^{69}$ Clarithromycin also was able to reduce viral titers and 
the content of cytokines in cultured human tracheal epithelial cells infected with influenza A virus (H3N2), along with the reduction in viral RNA in the cells, susceptibility to virus infection, and reduced NF-kB proteins. ${ }^{70}$ Clarithromycin's prophylactic and therapeutic efficacy was examined against avian influenza virus (H5N1) and (H7N9) infections in cynomolgus monkeys; it suppressed H5N1 virus-induced severe signs of disease in the treated monkeys. It also inhibited virus propagation in tracheal samples and the production of inflammatory cytokines in the lungs of monkeys infected with H5N1 and H7N9 viruses. ${ }^{71}$ The prophylactic administration of clarithromycin showed more suppressive effects on clinical signs of disease and viral titers than the therapeutic administration. ${ }^{71}$

Additionally, some tetracyclines also demonstrated activity against the influenza A virus, such as minocycline, which inhibited H7N9 influenza A virus replication in silico and in vitro. ${ }^{72}$ A combination of doxycycline with oseltamivir synergizes against swine flu (H1N1 influenza A virus) infection, ${ }^{73}$ while in vivo studies have indicated that treatment with doxycycline attenuates treatment attenuates acute lung injury in mice infected with virulent influenza H3N2 virus. ${ }^{74}$ On the other hand, rifampicin showed inconsistent findings as it was able to inhibit hemagglutinating and infective virus yields of influenza $\mathrm{A} / \mathrm{PR} / 8 / 34$ (HONl) infection in embryonated eggs, ${ }^{75}$ but the drug showed limited activity against the virus in vivo. ${ }^{76}$

Some antifungal drugs also showed activity against influenza A viruses as in an in vitro study itraconazole and posaconazole efficiently inhibited the propagation of Influenza A virus (IAV) in the cell culture model without being cytotoxic. The mode of action of itraconazole was suggested to be based on several targets and includes both priming of the interferon response and the induced imbalance of cellular cholesterol. Also, the antiviral effect of itraconazole was confirmed in the mouse model, where the administration of itraconazole led to a drastic reduction in mortality and a significant increase in the survival rate. ${ }^{77}$

Influenza A virus replication was also inhibited by the antimalarial drug chloroquine in vitro, with the IC50s of chloroquine against influenza A viruses $\mathrm{H} 1 \mathrm{~N} 1$ and $\mathrm{H} 3 \mathrm{~N} 2$ being lower than the plasma concentrations reached during treatment of acute malaria. ${ }^{78}$ Quinine also showed activity against influenza A virus, as it showed slight but consistent inhibiting activity on the course of influenza virus infection in mice, ${ }^{79}$ This activity against influenza A virus was also observed against the strain H1N1/2009 virus replication in vitro, with both chloroquine and quinine being identified as lysosomotropic alkalinizing agent. ${ }^{80}$

\section{Drugs Acting on Picornaviridae Viruses}

Some macrolide antibiotics demonstrated activity against some picornaviridae viruses, such as azithromycin, which was documented to possess anti-rhinoviral activity in bronchial epithelial cells as shown in a study that used in vitro models of normal primary human bronchial epithelial cell (HBEC) culture. ${ }^{16}$ It significantly reduced rhinovirus replication and release; the drug also increased rhinovirus-1B and rhinovirus-16 induced interferons and interferon-stimulated gene mRNA expression and protein production. ${ }^{81}$ Another drug is clarithromycin which showed effect on rhinovirus infection in A549 alveolar epithelial cells in vitro, the study documented that clarithromycin could inhibit the rhinovirus induced increase in intercellular adhesion molecule (ICAM-1) mRNA and protein, as well as the rhinovirus induced secretion of IL-1b, IL-6, and IL-8, and an overall reduction in rhinovirus titer, with the degree of reduction in virus titer being greater in cells pretreated with clarithromycin than in cells administered with clarithromycin at the time of the infection. ${ }^{82}$ Another study also documented the ability of clarithromycin to inhibit rhinovirus-induced expression of host cell adhesion molecules, including fibronectin and carcinoembryonic antigen-related cell adhesion molecules, subsequently preventing secondary bacterial infections in rhinovirus infected cells. ${ }^{83}$ Despite these positive in vitro findings, a randomized, double-blind, controlled clinical trial showed that clarithromycin treatment has little or no effect on the severity of cold symptoms or the intensity of neutrophilic nasal inflammation in experimental rhinovirus- 16 colds. Many factors could have accounted for the lack of anti-inflammatory effect in this clinical study, such as the nature of the stimulus used, interspecies differences, variations in the response of the nasal and tracheal airways, and the effect of the duration of antibiotic therapy on the immune response. ${ }^{84}$ Erythromycin also showed the ability to reduce the viral titers and RNA of rhinovirus in infected cultured human tracheal epithelial cells in vitro. Also, it decreased the number of acidic endosomes in the infected epithelial cells. It was suggested that erythromycin inhibits rhinovirus infection by reducing ICAM-1, partly due to the inhibition of activated NF-kB and blocking the rhinovirus RNA entry into the 
endosomes. ${ }^{85}$ Another study of the effect of erythromycin on rhinovirus infected human tracheal epithelial cells documented that erythromycin was able to block rhinovirus-induced Mucin 5AC (MUC5AC) protein over production and hypersecretion, and also blocked rhinovirus-induced mitogen-activated protein kinase (p44/42 MAPK) activation in the cells. ${ }^{86}$

Levofloxacin pretreatment of human tracheal epithelial cells infected with rhinoviruses decreased the mRNA level of ICAM-1 in the cells and the concentration of the soluble form of ICAM-1 in the supernatant before rhinovirus infection, it also decreased the number of the detected acidic endosomes from which rhinovirus RNA enters the cytoplasm, and inhibited the activation of NF-kB proteins in nuclear extracts. ${ }^{87}$ In vitro study documented that sodium fusidate inhibited both rhinoviruses and coxsackie virus A21 in human embryo lung cells and certain strains of an attenuated poliovirus type 1 in HeLa cells. Despite these in vitro findings, sodium fusidate was unsuccessful in preventing coxsackie virus A21 infection in vivo. ${ }^{88}$

Dalbavancin, a glycopeptide antibacterial agent, was also documented as an inhibitor for replication of echovirus 1 , which is another member of picornaviridae most probably by inhibiting its entry to the cells. ${ }^{89}$ Another drug that affected viruses from the picornaviridae is minocycline which was documented to have anti-inflammatory and antiviral effects in enterovirus 71 infection, as the drug showed a reduction in cytokines, and inhibition of IL-6 and granulocyte colonystimulating factor (G-CSF) in plasma and tumor necrosis factor (TNF) in the cerebellum, also in vivo animal model showed a decrease in mortality rates and viral titers in various brain tissues after minocycline treatment. ${ }^{90}$

Reviewing the effect of antifungal drugs against picornaviridae viruses showed that itraconazole have a wide range of activity, for instance, human rhinovirus replication was reduced by itraconazole in vivo in infected mice model, the drug also was able to suppress the inflammation associated with human rhinovirus infection as there was a reduction in the number of immune cells in bronchoalveolar lavage fluid corresponding to decreased pro-inflammatory cytokine and chemokine levels. Moreover, itraconazole nasal spray exhibited potent prophylactic antiviral activity against human rhinovirus in vivo in mice model. ${ }^{91}$ In another study, itraconazole was also identified as an effective inhibitor of enterovirus 71 replication and other enteroviruses, including coxsackievirus A16, coxsackievirus B3 poliovirus 1, and enterovirus 68. It was proposed that the drug targets a step involved in RNA replication or polyprotein. ${ }^{92}$ Itraconazole also demonstrated great potency against echovirus 30 as concentration a dependent activity. It was suggested that the drug affected the initial stages of echovirus 30 infection through interference with viral replication, ${ }^{93}$ the antiviral activity of itraconazole against parechovirus A3 was also confirmed in an in vitro study. ${ }^{94}$

Other antifungal drugs also showed activity against picornaviridae viruses, such as posaconazole which have a molecular structure similar to that of itraconazole, as it exhibited anti-enterovirus 71 activity without being subject to cross-resistance from itraconazole-resistant viruses. ${ }^{92}$ Also, an in vitro automated homogeneous cell-based assay study identified posaconazole as an inhibitor of parechovirus A3 virus. ${ }^{94}$ Additionally, amphotericin B inhibited enterovirus 71 production parallel to profoundly diminishing the expression of viral RNA and viral proteins in vitro. Mechanistic studies revealed that Amphotericin B targeted the early stage of enterovirus 71 infections by impairing the virus's attachment and internalizations by host cells. ${ }^{95}$ Micafungin also showed a potent inhibitory effect on the proliferation of enterovirus 71 as well as the replication of enterovirus 71 replicons in cells. ${ }^{96}$

Some picornaviridae viruses also showed sensitivity toward chloroquine, as the drug showed the ability to redirect the processing of input virions without interfering with productive uncoating, as shown in an in vitro experiment against poliovirus type 1, in which chloroquine redirected the production of eclipse products from 135 and $110 \mathrm{~S}$ particles (containing RNA) to 80S particles (without RNA) meanwhile viral protein synthesis and virion production remained unaffected. ${ }^{97}$ Moreover, chloroquine also showed activity in in vitro studies against enterovirus $71 .{ }^{98,99}$

\section{Drugs Acting on Retroviridae Viruses}

Many in vitro and in vivo studies were conducted to assess the antiviral effect of minocycline against some Retroviridae viruses. An in vivo study about the effect of minocycline on simian immunodeficiency virus (SIV) infected pigtailed macaques showed that minocycline was able to reduce the severity of encephalitis associated with SIV infection, suppressed viral load in the brain, and decreased the expression of CNS inflammatory markers, also cell culture In vitro study showed that minocycline inhibited SIV and HIV replication. ${ }^{100}$ Another study on treating SIV-infected rhesus 
macaques with minocycline showed that the drug exhibited significant neuroprotection associated with a decrease in cerebrospinal and plasma viral loads. ${ }^{101}$ Besides, minocycline which has antioxidant activity, also has a protective effect on dopamine homeostasis when administered at an appropriate time in SIV neuropathogenesis. ${ }^{102}$ Another study on the effect of minocycline on HIV infection suggested that minocycline could be included in the class of anticellular anti-HIV drugs as the antiviral effects of the drug were found to be mediated by altering the cellular environment rather than directly targeting virus, it was found that minocycline mediated a dose-dependent decrease in single-cycle $\mathrm{C}-\mathrm{X}$ - $\mathrm{C}$ chemokine receptor type 4 (CXCR4) tropic HIV infection and decreased viral RNA after infection of CD4+ T cells with HIV NL4-3, viral reactivation from latency was also decreased in a primary CD4+ T cell-derived model and in resting CD4+ T cells from HIV infected patients, generally minocycline treatment resulted in significant changes in activation marker expression and inhibited proliferation and cytokine secretion of CD4+ $\mathrm{T}$ cells in response to activation, ${ }^{103}$ Furthermore, another research also documented that treatment with minocycline resulted in a significant decrease of expression of cellular and plasma immune activation markers, inhibition of HIV replication and improved T-cell counts in HIV-infected humanized NOD scid gamma (NSG) mice. ${ }^{104}$ On the other hand, an early report documented the antiviral activity of both minocycline and doxycycline against HIV in human acute lymphoblastic T-cell leukemia CEM cells. ${ }^{105,106}$ Furthermore, results of an in vitro study showed that doxycycline possesses antimurine retrovirus activity as it was able to reduce the viral titer at a concentration usually achieved in serum to obtain antibacterial activity. ${ }^{107}$

Some other antibacterial drugs also showed activity against the human immunodeficiency virus, such as neomycin which demonstrated ability to inhibit HIV production in a chronically infected cell line. The drug showed the ability to block binding of the HIV Rev (regulator of expression of virion) protein (one of the viral regulatory proteins) to its viral RNA recognition element, which could be correlated to its antiviral action. ${ }^{108}$ Another HIV-1 regulatory protein, HIV-1 Tat (trans-activator of transcription), was also subject to neomycin action as the drug was able to inhibit the binding of Tat-derived peptides to the trans-activating region (TAR) of HIV-1 RNA. ${ }^{109-111}$ Also, an in vitro study using a line of lymphoblastic cells (CEM cells) to evaluate the effect of ofloxacin on HIV-1 infection showed that the drug protected the infected cells from HIV-1-mediated cytolysis, and it was detected that the D-isomer of ofloxacin was about 50-fold less effective than the L-isomer. ${ }^{112}$ Also, the direct anti-HIV activity of fusidic acid was demonstrated in vitro as the drug resulted in inhibition of syncytial formation and reverse transcriptase (RT) of viruses from three isolates (CBL-1, H9RF, and ARV-2) in C8166 cells. ${ }^{113}$ Another study confirmed the effect of fusidic acid on HIV infection as it showed that fusidic acid reduced the reverse transcriptase levels in supernatants of HIV-1 infected cell cultures. ${ }^{114}$ Despite these promising results, another study documented that fusidic acid was ineffective against HIV in both in vivo and in vitro human and murine assay systems. ${ }^{115}$ Another drug that showed activity against HIV is gramicidin, which is antiviral in vitro was documented in previous research. ${ }^{116,117}$ Finally, it was also found that L-cycloserine (L-CS) inhibits HIV-1 replication in a CD4+ lymphoid cell line (CEM) as documented by the reduction of syncytium formation, the number of HIV-1 infected cells, and p24 protein production. ${ }^{118}$

On the other hand, several researches investigated the effect of chloroquine and hydroxychloroquine on HIV. An early in vitro study showed that treatment of HIV-1 and avian reticuloendotheliosis virus (REV-A) infected cells with chloroquine resulted in a significant size reduction of the cell and virus-associated surface glycoproteins, gp90 of REV-A and gpl20 of HIV-1, also chloroquine treatment resulted in the majority of the virions released being noninfectious and the total virus yield was also reduced, and the understanding of the obtained data suggested that chloroquine inhibition of infectious virus production is most likely due to interference with terminal glycosylation in the trans-Golgi network. ${ }^{119}$ Moreover, chloroquine showed an additive antiretroviral effect in vitro when combined with didanosine and hydroxyurea. ${ }^{120}$ Chloroquine also showed activity against HIV-1 integrase. ${ }^{121}$ Additionally, a previous in vitro study stated that chloroquine inhibits HIV-1 post integrationally by affecting newly produced viral envelope glycoproteins, and the drug has broad-spectrum anti-HIV-1 and HIV-2 activity at clinically achievable concentrations. ${ }^{122}$ Also, a clinical observation study stated that random maternal chloroquine use might be associated with a decreased rate of HIV vertical transmission. ${ }^{123}$ Moreover, it was shown that chloroquine reduced HIV-1 replication in CD4+ T-lymphocytes, associated with modulation of the gp120 structure, and HIV-1 produced in the presence of chloroquine characterized by reduced capacity for transfer by Raji-DC-SIGN cells to CD4+ T-lymphocytes. ${ }^{124}$ Hydroxychloroquine 
also showed ability to suppress HIV-1 replication in vitro in T cells and monocytes by inhibiting post-transcriptional modification of the virus; also a randomized, double-blind, placebo-controlled clinical trial showed that the amount of recoverable HIV-1 RNA in plasma of hydroxychloroquine treated patients declined significantly. ${ }^{125}$ Another in vitro study also confirmed the inhibitory effect of hydroxychloroquine on HIV-1 replication in the primary T cells and monocytes as well as the T cell and monocytic cell lines. ${ }^{126}$ Other clinical observations also support the suggestion of the usefulness of treating HIV-1 infected patients with hydroxychloroquine. ${ }^{127}$ Further in vitro investigation showed that hydroxychloroquine demonstrates anti-HIV activity by increasing endosomal $\mathrm{pH}$ in a dose-dependent manner similar to that of chloroquine which inhibits the post-transcriptional production of gpl20. ${ }^{128}$

Pyrimethamine, another antiprotozoal medication, demonstrated in vitro antiviral activity against HIV. It was documented that pyrimethamine significantly enhances HIV-1 replication by affecting the cellular machinery, facilitating S-phase accumulation. However, it also showed the ability to potentiate the susceptibility of HIV to antiretroviral therapy as it increased zidovudine and stavudine antiviral activity by approximately 4 -folds. ${ }^{129}$

\section{Drugs Acting on Togaviridae Viruses}

Few studies were conducted to evaluate the antiviral activity of some antimicrobial agents against members of the Togaviridae family. For instance, an in vitro study documented that doxycycline showed a high ability to inhibit chikungunya virus (CHIKV) infectivity and entry, also docking studies of doxycycline to viral cysteine protease and E2 envelope protein showed non-competitive interaction. Besides, assays using mice as animal models revealed that a combination of doxycycline and ribavirin effectively inhibited CHIKV replication and attenuated its infectivity in vivo. ${ }^{130}$ Also, a study in a murine model of fatal alphavirus encephalomyelitis showed that minocycline displayed significant protection against both paralysis and death, even when started after viral challenge, and despite having no effect on CNS virus replication or spread, it was also documented that minocycline inhibited early virus-induced microglial activation, in addition, the diminished CNS production of the inflammatory mediator interleukin (IL)- $1 \beta$ contributed to its protective effect. ${ }^{131}$

Some antifungal drugs also showed activity against Togaviridae viruses, such as micafungin, which showed the ability to counter CHIKV induced cytopathic effects. It was able to limit virus replication and release cell-to-cell transmission and slightly affected virus stability at high doses treatment. In silico studies indicated that micafungin could bind with CHIKV envelope proteins. Moreover, micafungin showed in vitro inhibitory effect against Sindbis virus and Semliki forest virus. ${ }^{132}$ Also, amphotericin B in a formulation with sodium deoxycholate (an emulsifying agent) inhibited plaque formation by rubella virus in rabbit kidney 13 cells in both size and number, and the antiviral effect observed on rubella virus was attributable to amphotericin B. ${ }^{133}$

Other drugs that affected Togaviridae viruses include atovaquone which showed antiviral activity against CHIKV in Vero cells at small concentrations, and the observed antiviral effect was suggested to be via depletion of nucleotides blocking pyrimidine biosynthesis. ${ }^{47}$ Another study also confirmed this inhibitory effect of atovaquone on chikungunya virion production in human cells and stated that the antiviral effect of the drug occurred early during infection at the initial steps of viral RNA replication. ${ }^{48}$ Moreover, chloroquine also showed in vitro activities against $\mathrm{CHIKV}^{49,134,135}$

\section{Drugs Acting on Polyomaviridae Viruses}

Most of the drugs that showed activity against Polyomaviridae viruses were members of the quinolone antibacterial agents. Starting from ciprofloxacin, for which a clinical observation report documented that progressive reduction in human polyomavirus BK (BKV) replication was observed in a patient who underwent ciprofloxacin treatment concurrently with an increase of immunosuppressive therapy, the effect was detected as a decrease in the BKV load in both urinary and circulatory compartments. ${ }^{136}$ This observation came in line with other previous clinical cases that showed the ability of ciprofloxacin to decrease BKV load in patients who underwent transplantation. ${ }^{137-139}$ Aside from clinical observations, in vitro study also documented the effect of ciprofloxacin on BKV, as ciprofloxacin was able to inhibit the viral replication in infected cultured salivary gland cells and Vero cells. It was able to decrease $\mathrm{T}$ antigen ( $\mathrm{T} \mathrm{Ag}$ ) and capsid protein (VP1) mRNA expression associated with a decrease in T Ag protein expression and intracellular DNA replication and decrease in progeny release. ${ }^{140}$ This finding was augmented with another study that documented the 
antiviral activity of ciprofloxacin against the BK virus, as the drug showed the ability to inhibit the viral replication in the in vitro culture in Vero cell line. ${ }^{141}$ Although some findings suggest that the effect of ciprofloxacin on BKV is only modest with a selectivity index lower than 10.0 (the ratio of the 50\% reduction in host cell replication value to the $50 \%$ virus inhibitory concentration value), it was still proposed that ciprofloxacin might be more effective as prophylaxis against hemorrhagic cystitis caused by BKV. ${ }^{142}$ Additionally, both ciprofloxacin, levofloxacin, and ofloxacin were effective in the inhibition of simian virus 40 (SV40) plaque formations and DNA replication in CV1-P cell line. It was inhibitory to the helicase activity of SV40 large tumor antigen, suggesting that the drug might be useful in the treatment and/or prevention of infection by SV40 homologous human DNA viruses that encode helicase activity for their survival. ${ }^{143}$

Also, regarding the effect of levofloxacin, a clinical observation study of BKV associated hemorrhagic cystitis patients, it was documented that the hemorrhagic cystitis was resolved in the observed patients using oral levofloxacin. ${ }^{144}$ On the other hand, there were inconsistent clinical results about the effect of levofloxacin on BKV viral load, as on one side, it was found that the prophylactic effect of levofloxacin against BKV viremia was observed clinically. ${ }^{139}$ In contrast, another clinical observation did not support the use of levofloxacin to decrease BKV viral infection in the posttransplant setting as it did not show an effect on BKV viruria, but there was increased bacterial resistance in the levofloxacin group. ${ }^{145}$ In vitro studies about the effect of levofloxacin on the replication of BKV in renal proximal tubular epithelial cells (RPTECs) revealed that although levofloxacin does not eradicate BKV replication in RPTECs, it could inhibit BKV viral load in a dose-dependent manner associated with inhibition of cellular DNA replication and total metabolic activity without significant host cell cytotoxicity, with a suggestion that the action may be associated with inhibition of BKV large T antigen (LT-Ag) protein expression or function and inhibition of cellular enzymes. ${ }^{146}$

Mefloquine showed the ability to inhibit the viral infection rates of a range of John Cunningham virus (JC virus) isolates in different cell types without blocking viral cell entry; instead, it inhibits viral replication in cells after viral entry. ${ }^{147}$ Although later on, a review for the clinical study researches about the therapeutic effect of mefloquine against JC virus showed contradictory results. ${ }^{148}$ Fusidic acid also showed antiviral activity against the JC virus in vitro and clinically in a case report. ${ }^{147,149}$

\section{Drugs Acting on Other DNA Viruses}

Viruses in this category include vaccinia virus, poxvirus, adenoviruses, and cyprinid herpes virus. Ofloxacin showed inhibitory activity against vaccinia virus both in vitro (in cultured mammalian cells) and in vivo (prevented the formation of pox tail lesions in vaccinia virus-infected mice). It was documented that ofloxacin is more inhibitory to vaccinia virus topoisomerase than cellular topoisomerases. ${ }^{150}$ Vaccinia virus was also sensitive toward rifampicin as the inhibitory effect of rifampicin against vaccinia virus replication has been documented in several previous studies. ${ }^{151-157}$ Also, in silico studies showed that rifampicin blocks the membrane-proximal channel and inhibits poxvirus viral morphogenesis. ${ }^{158}$ Moreover, an in vivo study on male hamsters stated that the proper use of rifampicin could affect the induction of tumors by adenovirus 12 in the animals. ${ }^{159}$ Finally, the antiviral activity of neomycin sulfate was also proved in bony fish (crucian carp) against cyprinid herpes virus- 2 as the drug was able to inhibit the viral replication and protect it from the infection. ${ }^{160}$

\section{Drugs Acting on Other RNA Viruses}

The reviewed studies in this section include research on the respiratory syncytial virus, Newcastle disease virus, rabies virus, vesicular stomatitis virus, rotavirus, reovirus, Ebola virus, rift valley fever phlebovirus, and Crimean-Congo hemorrhagic fever virus (CCHFV). One of the drugs to be mentioned is clarithromycin, which was able to reduce respiratory syncytial virus titers and viral RNA in infected human tracheal epithelial cells in an in vitro experimental model, reducing the susceptibility to respiratory syncytial virus infection and concentrations of cytokines induced by a virus infection. Clarithromycin exerts its inhibitory effect on respiratory syncytial virus partly through reducing expression of isoform A of the Rashomologus (Rho) family (RhoA), which is the receptor for respiratory syncytial virus fusion protein (F protein). ${ }^{161}$ Minocycline also reduced the respiratory syncytial virus-mediated cytopathic effect and prevented respiratory syncytial virus infection. ${ }^{162}$ It also showed the ability to delay disease onset and progression in reovirus encephalitis, even though it does not prevent the development of fatal reovirus encephalitis. It was suggested that the 
effect exerted by minocycline is more likely due to its anti-apoptotic properties. ${ }^{163}$ The drug also showed activity against the Rift valley fever virus in an in vitro screening. ${ }^{89}$

On the other hand, doxycycline showed activity against vesicular stomatitis virus as it was able to significantly inhibit vesicular stomatitis virus replication and the viral-induced cytopathic effect in a dose-dependent manner. It was noted that the drug exerted its antiviral effect at the early-mid stage of vesicular stomatitis virus infection, suggesting that it did not interfere with the virus infectivity, adsorption, or entry into target cells. ${ }^{164}$ Moreover, an in silico study proposed doxycycline as a potential inhibitor of CCHFV nucleoprotein. ${ }^{165}$ Neomycin also affected bovine rotavirus, reducing the virus cytopathogenicity, virus titer, and viral RNA concentration in a dose-dependent manner. ${ }^{166}$ Furthermore, glycopeptide antibacterial drugs demonstrated antiviral activity against the Ebola virus (EBOV), as results of an in vitro high throughput screening test for antiviral activity showed that teicoplanin, dalbavancin, oritavancin, and telavancin exhibit broad antiviral activity. They were able to affect the infection model of the envelope pseudotyped viruses representing EBOV by inhibiting virus entry to the cell through inhibiting cathepsin L enzymatic activity, which is essential for these viruses' entry. ${ }^{167}$ Another study confirmed the activity of teicoplanin as an inhibitor of EBOV pseudovirus in cell culture by blocking viral entry. ${ }^{168}$

Mefloquine was also identified as an effective blocker for EBOV entry and was further validated for inhibition of live EBOV infection. It was documented that the drug exhibited potent inhibition of NAADP-AM stimulated lysosomal calcium release and inhibited acid sphingomyelinase function. ${ }^{169}$ Another drug to be mentioned is primaquine which showed activity against Newcastle disease virus as the activity was observed in an in vitro study, in which the addition of primaquine inhibited the production of infectious progeny virus. It was reported that there was inhibition in viral ribonucleic acid synthesis when the drug was added early in the virus replication cycle, primaquine was also able to retard the incorporation of ${ }^{14} \mathrm{C}$ amino acids into proteins of virus-infected cells, and it was suggested that the major role of primaquine as antiviral is through inhibition of protein synthesis. ${ }^{170}$ Finally, pyrimethamine showed an inhibitory effect against rabies virus in vitro. Yet, it did not show efficacy when used for rabies infected-mice, and this was explained by a suggestion that the antiviral effect was negated by the observed interference of pyrimethamine with the innate immune response. ${ }^{171}$

\section{Perspectives and Conclusion}

Many published preclinical studies along with clinical observations and reports focused on the antiviral activity of approved drugs originally belonging to the antibacterial, antifungal, antiprotozoal, and anthelmintic categories. Although there is fear from losing the original activity of the drug due to resistance after repurposing for the antiviral activity, especially with antibacterial drugs, but seeing that many drugs have promising antiviral activity also encourages continuing the research in this area as it proved helpful in emergency and pandemic cases, with focusing also on constructing systematic guidance for research in this area to prevent drugs misuse and loss of original activity. Also, another useful approach is to consider these drugs as lead compounds and try to optimize their antiviral activity rather than the original activity for which they were approved. However, this approach was not encouraged due to fear that changes in the compound's chemical structure may lead to loss of the antiviral activity found. However, if it successfully goes, this may lead to discoveries for antiviral agents, mainly when focusing on drugs with multiple mechanisms for antiviral activity.

Regarding the mechanism of antiviral activity, some classes of drugs showed diversity in the mechanism of antiviral activity within their members, such as macrolide and tetracycline antibiotics. At the same time, some other classes showed uniformity in the mechanism of antiviral activity of their members, such as the azole antifungal drugs, quinolone antibiotics. One of the essential points that need focus is that many mechanistic researchers are taking the in silico approach, which is less time-consuming and provides information that other models cannot obtain. However, it will be more confirmative to have in vitro and in vivo models that strengthen the in silico studies' findings and give chances for observation of antiviral activity due to multiple or new mechanisms of action.

\section{Funding}

There is no funding to report. 


\section{Disclosure}

The authors declare that they have no conflicts of interest for this work.

\section{References}

1. Lateef Mousa HA. Prevention and treatment of viral infections by natural therapies. J Prev Infect Control. 2015;1(1):166-174. doi:10.21767/ 2471-9668.10004

2. Heymann DL, Dixon MA. Emerging and re-emerging infectious diseases. In: The Wiley Blackwell Encyclopedia of Health, Illness, Behavior, and Society. Wiley Online Library; 2014:474-479.

3. Mani D, Wadhwani A, Krishnamurthy PT. Drug repurposing in antiviral research: a current scenario. J Young Pharm. 2019;11(2):117-121. doi:10.5530/jyp.2019.11.26

4. Napoli PE, Mangoni L, Gentile P, Braghiroli M, Fossarello M. A panel of broad-spectrum antivirals in topical ophthalmic medications from the drug repurposing approach during and after the coronavirus disease 2019 era. J Clin Med. 2020;9(8):2441. doi:10.3390/jcm9082441

5. Mercorelli B, Palù G, Loregian A. Drug repurposing for viral infectious diseases: how far are we? Trends Microbiol. 2018;26(10):865-876. doi:10.1016/j.tim.2018.04.004

6. Li -C-C, Wang X-J, Wang H-CR. Repurposing host-based therapeutics to control coronavirus and influenza virus. Drug Discov Today. $2019 ; 24$ (3):726-736. doi:10.1016/j.drudis.2019.01.018

7. Narendrakumar L, Joseph I, Thomas S. Potential effectiveness and adverse implications of repurposing doxycycline in COVID-19 treatment. Expert Rev Anti Infect Ther. 2020;19(8):1001-1008. doi:10.1080/14787210.2021.1865803

8. Langeland N, Haarr L, Holmsen H. Evidence that neomycin inhibits HSV 1 infection of bhk cells. Biochem Biophys Res Commun. 1986;141 (1):198-203. doi:10.1016/S0006-291X(86)80354-0

9. Hung S-L, Wang Y-H, Chen H-W, Lee P-L, Chen Y-T. Analysis of herpes simplex virus entering into cells of oral origin. Virus Res. 2002;86(12):59-69. doi:10.1016/S0168-1702(02)00055-2

10. Langeland N, Holmsen H, Lillehaug JR, Haarr L. Evidence that neomycin inhibits binding of herpes simplex virus type 1 to the cellular receptor. J Virol. 1987;61(11):3388-3393. doi:10.1128/jvi.61.11.3388-3393.1987

11. Herold BC, Spear PG. Neomycin inhibits glycoprotein $\mathrm{C}(\mathrm{gC})$-dependent binding of herpes simplex virus type 1 to cells and also inhibits postbinding events in entry. Virology. 1994;203(1):166-171. doi:10.1006/viro.1994.1469

12. Skulason S, Holbrook WP, Thormar H, Gunnarsson GB, Kristmundsdottir T. A study of the clinical activity of a gel combining monocaprin and doxycycline: a novel treatment for herpes labialis. J Oral Pathol Med. 2012;41(1):61-67. doi:10.1111/j.1600-0714.2011.01037.x

13. Gopinath S, Kim MV, Rakib T, et al. Topical application of aminoglycoside antibiotics enhances host resistance to viral infections in a microbiota-independent manner. Nat Microbiol. 2018;3(5):611-621. doi:10.1038/s41564-018-0138-2

14. Mercorelli B, Luganini A, Celegato M, et al. The clinically approved antifungal drug posaconazole inhibits human cytomegalovirus replication. Antimicrob Agents Chemother. 2020;64(10):e0056-20. doi:10.1128/AAC.00056-20

15. Pottage JC, Kessler HA, Goodrich JM, et al. In vitro activity of ketoconazole against herpes simplex virus. Antimicrob Agents Chemother. 1986;30(2):215-219. doi:10.1128/AAC.30.2.215

16. Baroni A, Paoletti I, Ruocco E, et al. Antiviral effects of quinine sulfate on HSV-1 HaCat cells infected: analysis of the molecular mechanisms involved. J Dermatol Sci. 2007;47(3):253-255. doi:10.1016/j.jdermsci.2007.05.009

17. Wang X, Xia S, Zou P, Lu L. Erythromycin estolate inhibits zika virus infection by blocking viral entry as a viral inactivator. Viruses. 2019;11 (11):1064. doi:10.3390/v11111064

18. Bosseboeuf E, Aubry M, Nhan T, et al. Azithromycin inhibits the replication of zika virus. J Antivir Antiretrovir. 2018;10(1):6-11. doi:10.4172/ 1948-5964.1000173

19. Retallack H, Di Lullo E, Arias C, et al. Zika virus cell tropism in the developing human brain and inhibition by azithromycin. Proc Natl Acad Sci. 2016;113(50):14408-14413. doi:10.1073/pnas.1618029113

20. Lacerda MVG, Wu Y-H, Tseng C-K, et al. ICR suckling mouse model of Zika virus infection for disease modeling and drug validation. PLoS Negl Trop Dis. 2018;12(10):e0006848. doi:10.1371/journal.pntd.0006848

21. Yuan J, Yu J, Huang Y, et al. Antibiotic fidaxomicin is an RdRp inhibitor as a potential new therapeutic agent against Zika virus. BMC Med. 2020;18(1):204. doi:10.1186/s12916-020-01663-1

22. Michaelis M, Kleinschmidt MC, Doerr HW, Cinatl J. Minocycline inhibits West Nile virus replication and apoptosis in human neuronal cells. $J$ Antimicrob Chemother. 2007;60(5):981-986. doi:10.1093/jac/dkm307

23. Quick ED, Seitz S, Clarke P, Tyler KL, Perlman S. Minocycline has anti-inflammatory effects and reduces cytotoxicity in an ex vivo spinal cord slice culture model of west Nile virus infection. $J$ Virol. 2017;91(22):e00569-17. doi:10.1128/JVI.00569-17

24. Mishra MK, Basu A. Minocycline neuroprotects, reduces microglial activation, inhibits caspase 3 induction, and viral replication following Japanese encephalitis. J Neurochem. 2008;105(5):1582-1595. doi:10.1111/j.1471-4159.2008.05238.x

25. Mishra MK, Ghosh D, Duseja R, Basu A. Antioxidant potential of Minocycline in Japanese Encephalitis Virus infection in murine neuroblastoma cells: correlation with membrane fluidity and cell death. Neurochem Int. 2009;54(7):464-470. doi:10.1016/j.neuint.2009.01.022

26. Egli M, Yang J-M, Chen Y-F, Tu -Y-Y, Yen K-R, Yang Y-L. Combinatorial computational approaches to identify tetracycline derivatives as flavivirus inhibitors. PLoS One. 2007;2(5):e428. doi:10.1371/journal.pone.0000428

27. Rothan HA, Mohamed Z, Paydar M, Rahman NA, Yusof R. Inhibitory effect of doxycycline against dengue virus replication in vitro. Arch Virol. 2013;159(4):711-718. doi:10.1007/s00705-013-1880-7

28. Khan IA, Siddiqui S, Rehmani S, Kazmi SU, Ali SH. Fluoroquinolones inhibit HCV by targeting its helicase. Antivir Ther. 2011;17(3):467-476. doi:10.3851/IMP1937

29. Takada A, Takase S, Tsutsumi M, Sawada M. Effects of ofloxacin for type C hepatitis. Int Hepatol Commun. 1993;1(5):272-277. doi:10.1016/ 0928-4346(93)90075-Q

30. Tsutsumi M, Takada A, Takase S, Sawada M. Effects of combination therapy with interferon and ofloxacin on chronic type C hepatitis: a pilot study. J Gastroenterol Hepatol. 1996;11(11):1006-1011. doi:10.1111/j.1440-1746.1996.tb00022.x 
31. Komatsu M, Ishii T, Ono T, et al. Pilot study of ofloxacin and interferon-alpha combination therapy for chronic hepatitis C without sustained response to initial interferon therapy. Can J Gastroenterol. 1997;11(6):507-511. doi:10.1155/1997/627297

32. Negro F, Male P-J, Perrin L, Gistra E, Hadengue A. Treatment of chronic hepatitis C with $\alpha$-interferon plus ofloxacin in patients not responding to $\alpha$-interferon alone. J Hepatol. 1998;29(3):369-374. doi:10.1016/S0168-8278(98)80053-6

33. Barrows Nicholas J, Campos Rafael K, Powell ST, et al. A screen of FDA-approved drugs for inhibitors of zika virus infection. Cell Host Microbe. 2016;20(2):259-270. doi:10.1016/j.chom.2016.07.004

34. Hun K, Kim S-J, Park S-N, Oh A-W. Antiviral effect of amphotericin B on Japanese encephalitis virus replication. J Microbiol Biotechnol. 2004;14(1):121-127.

35. Kessler HA, Dixon J, Howard CR, Tsiquaye K, Zuckerman AJ. Effects of amphotericin B on hepatitis B virus. Antimicrob Agents Chemother. 1981;20(6):826-833. doi:10.1128/AAC.20.6.826

36. Pottage JC, Kessler HA. Inhibition of in vitro HBsAg production by amphotericin B and ketoconazole. J Med Virol. 1985;16(3):275-281. doi:10.1002/jmv.1890160308

37. Jin $\mathrm{H}$, Yamashita A, Maekawa S, et al. Griseofulvin, an oral antifungal agent, suppresses hepatitis $\mathrm{C}$ virus replication in vitro. Hepatol Res. 2008;38(9):909-918. doi:10.1111/j.1872-034X.2008.00352.x

38. Meutiawati F, Bezemer B, Strating JR, et al. Posaconazole inhibits dengue virus replication by targeting oxysterol-binding protein. Antiviral Res. 2018;157:68-79. doi:10.1016/j.antiviral.2018.06.017

39. Balasubramanian A, Teramoto T, Kulkarni AA, Bhattacharjee AK, Padmanabhan R. Antiviral activities of selected antimalarials against dengue virus type 2 and Zika virus. Antiviral Res. 2017;137:141-150. doi:10.1016/j.antiviral.2016.11.015

40. Farias KJS, Machado PRL, Muniz JA, Imbeloni AA, da Fonseca BAL. Antiviral activity of chloroquine against dengue virus type 2 replication in aotus monkeys. Viral Immunol. 2015;28(3):161-169. doi:10.1089/vim.2014.0090

41. Farias KJS, Machado PRL, De almeida Junior RF, de Aquino AA, da Fonseca BAL. Chloroquine interferes with dengue-2 virus replication in U937 cells. Microbiol Immunol. 2014;58(6):318-326. doi:10.1111/1348-0421.12154

42. Farias KJS, Machado PRL, da Fonseca BAL. Chloroquine inhibits dengue virus type 2 replication in Vero cells but not in C6/36 cells. Sci World J. 2013;2013:1-5. doi:10.1155/2013/282734

43. Shiryaev SA, Mesci P, Pinto A, et al. Repurposing of the anti-malaria drug chloroquine for Zika Virus treatment and prophylaxis. Sci Rep. 2017;7(1):15771. doi:10.1038/s41598-017-15467-6

44. Delvecchio R, Higa LM, Pezzuto P, et al. Chloroquine, an endocytosis blocking agent, inhibits zika virus infection in different cell models. Viruses. 2016;8(12):322. doi:10.3390/v8120322

45. Chandramohan M, Vivekananthan SC, Sivakumar D, et al. Preliminary report of anti-hepatitis C virus activity of chloroquine and hydroxychloroquine in huh-5-2 cell line. Indian J Pharm Sci. 2006;68(4):538-540. doi:10.4103/0250-474X.27842

46. Mizui T, Yamashina S, Tanida I, et al. Inhibition of hepatitis C virus replication by chloroquine targeting virus-associated autophagy. $J$ Gastroenterol. 2009;45(2):195-203. doi:10.1007/s00535-009-0132-9

47. Kottkamp A, DeJesus E, Stapleford K. 1895. The anti-parasitic drug atovaquone inhibits arbovirus replication. Open Forum Infect Dis. 2018;5 (suppl_1):S543-S543. doi:10.1093/ofid/ofy210.1551

48. Cifuentes kottkamp A, De Jesus E, Grande R, et al. Atovaquone inhibits arbovirus replication through the depletion of intracellular nucleotides. J Virol. 2019;93(11):e00389-19. doi:10.1128/JVI.00389-19

49. Ozden S, Lucas-Hourani M, Ceccaldi PE, et al. Inhibition of Chikungunya virus infection in cultured human muscle cells by furin inhibitors: impairment of the maturation of the E2 surface glycoprotein. J Biol Chem. 2008;283(32):21899-21908. doi:10.1074/jbc.M802444200

50. Wu C, Liu Y, Yang Y, et al. Analysis of therapeutic targets for SARS-CoV-2 and discovery of potential drugs by computational methods. Acta Pharmaceutica Sinica B. 2020;10(5):766-788. doi:10.1016/j.apsb.2020.02.008

51. Gautret P, Lagier J-C, Parola P, et al. Hydroxychloroquine and azithromycin as a treatment of COVID-19: results of an open-label nonrandomized clinical trial. Int J Antimicrob Agents. 2020;56(1):105949. doi:10.1016/j.ijantimicag.2020.105949

52. Molina JM, Delaugerre C, Le Goff J, et al. No evidence of rapid antiviral clearance or clinical benefit with the combination of hydroxychloroquine and azithromycin in patients with severe COVID-19 infection. Médecine et Maladies Infectieuses. 2020;50(4):384. doi:10.1016/j. medmal.2020.03.006

53. Andreani J, Le Bideau M, Duflot I, et al. In vitro testing of combined hydroxychloroquine and azithromycin on SARS-CoV-2 shows synergistic effect. Microb Pathog. 2020;145:104228. doi:10.1016/j.micpath.2020.104228

54. Touret F, Gilles M, Barral K, et al. In vitro screening of a FDA approved chemical library reveals potential inhibitors of SARS-CoV-2 replication. Sci Rep. 2020;10(1):1-8. doi:10.1038/s41598-020-70143-6

55. Poschet JF, Perkett EA, Timmins GS, Deretic V. Azithromycin and ciprofloxacin have a chloroquine-like effect on respiratory epithelial cells. bioRxiv. 2020. doi:10.1101/2020.03.29.008631

56. Parvez M, Alam S, Karim M, et al. Prediction of potential inhibitors for RNA-dependent RNA polymerase of SARS-CoV-2 using comprehensive drug repurposing and molecular docking approach. Info Med Unlocked. 2020;163:1787-1797.

57. Marciniec K, Beberok A, Pęcak P, Boryczka S, Wrześniok D. Ciprofloxacin and moxifloxacin could interact with SARS-CoV-2 protease: preliminary in silico analysis. Pharmacol Rep. 2020;72(6):1553-1561. doi:10.1007/s43440-020-00169-0

58. Yu D, Sun S, Li Y, et al. Treatment with arbidol and moxifloxacin in ordinary and severe adult patients infected with COVID-19. medRxiv. 2020. doi:10.1101/2020.05.30.20117598

59. Pathak Y, Mishra A, Tripathi V. Rifampicin may be repurposed for COVID-19 treatment: insights from an in-silico study. PREPRINT. 2020. doi:10.1101/2020.05.30.20117598

60. Ke -Y-Y, Peng -T-T, Yeh T-K, et al. Artificial intelligence approach fighting COVID-19 with repurposing drugs. Biomed J. 2020;43:355-362. doi:10.21203/rs.3.rs-22546/v1

61. Mirabelli C, Wotring JW, Zhang CJ, et al. Morphological cell profiling of SARS-CoV-2 infection identifies drug repurposing candidates for COVID-19. bioRxiv. 2020. doi:10.1101/2020.05.27.117184

62. Liu X, Wang X-J. Potential inhibitors against 2019-nCoV coronavirus M protease from clinically approved medicines. J Genet Genom. 2020;47 (2):119-121. doi:10.1016/j.jgg.2020.02.001 
63. Wang M, Ye F, Su J, et al. Caspofungin and LTX-315 inhibit SARS-CoV-2 replication by targeting the nsp12 polymerase. PREPRINT. 2020. doi:10.21203/rs.3.rs-19872/v1

64. Olaleye OA, Kaur M, Onyenaka C, Adebusuyi T. Discovery of clioquinol and analogues as novel inhibitors of severe acute respiratory syndrome coronavirus 2 infection, ACE2 and ACE2 - spike protein interaction in vitro. bioRxiv. 2020. doi:10.1101/2020.08.14.250480

65. Ayman F, Ping W, Ian NB, et al. Identification of atovaquone, ouabain and mebendazole as FDA approved drugs targeting SARS-CoV-2 (Version 4). ChemRxiv Preprint. 2020. doi:10.33774/chemrxiv-2021-b3fv1-v7

66. Tran DH, Sugamata R, Hirose T, et al. Azithromycin, a 15-membered macrolide antibiotic, inhibits influenza A(H1N1)pdm09 virus infection by interfering with virus internalization process. J Antibiot (Tokyo). 2019;72(10):759-768. doi:10.1038/s41429-019-0204-x

67. Cameron DW, Kakeya H, Seki M, et al. Efficacy of combination therapy with oseltamivir phosphate and azithromycin for influenza: a multicenter, open-label, randomized study. PLoS One. 2014;9(3):e91293. doi:10.1371/journal.pone.0091293

68. Ishaqui AA, Khan AH, Sulaiman SAS, Alsultan MT, Khan I, Naqvi AA. Assessment of efficacy of Oseltamivir-Azithromycin combination therapy in prevention of Influenza-A (H1N1)pdm09 infection complications and rapidity of symptoms relief. Expert Rev Respir Med. $2020 ; 14$ (5):533-541. doi:10.1080/17476348.2020.1730180

69. Miyamoto D, Hasegawa S, Sriwilaijaroen N, et al. Clarithromycin inhibits progeny virus production from human influenza virus-infected host cells. Biol Pharm Bull. 2008;31(2):217-222. doi:10.1248/bpb.31.217

70. Yamaya M, Shinya $\mathrm{K}$, Hatachi $\mathrm{Y}$, et al. Clarithromycin inhibits type A seasonal influenza virus infection in human airway epithelial cells. $J$ Pharmacol Exp Therap. 2010;333(1):81-90. doi:10.1124/jpet.109.162149

71. Arikata M, Itoh Y, Shichinohe S, et al. Efficacy of clarithromycin against H5N1 and H7N9 avian influenza a virus infection in cynomolgus monkeys. Antiviral Res. 2019;171:104591. doi:10.1016/j.antiviral.2019.104591

72. Josset L, Zeng H, Kelly SM, Tumpey TM, Katze MG. Transcriptomic characterization of the novel avian-origin influenza A (H7N9) virus: specific host response and responses intermediate between avian (H5N1 and H7N7) and human (H3N2) viruses and implications for treatment options. mBio. 2014;5(1):e01102-13.

73. Quispe-Laime AM, Bracco JD, Barberio PA, et al. H1N1 influenza A virus-associated acute lung injury: response to combination oseltamivir and prolonged corticosteroid treatment. Intensive Care Med. 2009;36(1):33-41. doi:10.1007/s00134-009-1727-6

74. Ng HH, Narasaraju T, Phoon MC, Sim MK, Seet JE, Chow VT. Doxycycline treatment attenuates acute lung injury in mice infected with virulent influenza H3N2 virus: involvement of matrix metalloproteinases. Exp Mol Pathol. 2012;92(3):287-295. doi:10.1016/j. yexmp.2012.03.003

75. And MH, Ledinko N. Inhibition of influenza a virus replication by rifampicin and selenocystamine. J Med Virol. 1980;6(2):169-174

76. Richert NJ, Balduzzi P. Mechanism of oncogenic transformation by Rous sarcoma virus. II. Effect of rifampin on Rous sarcoma virus infection. J Virol. 1971;8(1):62-65. doi:10.1128/jvi.8.1.62-65.1971

77. Schloer S, Goretzko J, Kühnl A, Brunotte L, Ludwig S, Rescher U. The clinically licensed antifungal drug itraconazole inhibits influenza virus in vitro and in vivo. Emerg Microbes Infect. 2019;8(1):80-93. doi:10.1080/22221751.2018.1559709

78. Ooi E, Chew J, Loh J, Chua RCS. In vitro inhibition of human influenza A virus replication by chloroquine. Virol J. 2006;3(1):1-3. doi:10.1186/ 1743-422X-3-39

79. Seeler AO, Graessle O, Ott WH. Effect of quinine on influenza virus infections in mice. J Infect Dis. 1946;79(2):156-158. doi:10.1093/infdis/ 79.2.156

80. Kashanchi F, Marois I, Cloutier A, et al. Inhibition of influenza virus replication by targeting broad host cell pathways. PLoS One. 2014;9(10): e110631. doi:10.1371/journal.pone.0110631

81. Gielen V, Johnston SL, Edwards MR. Azithromycin induces antiviral responses in bronchial epithelial cells. Eur Respir J. 2010;36(3):646-654. doi:10.1183/09031936.00095809

82. Jang YJ. Effect of clarithromycin on rhinovirus-16 infection in A549 cells. Eur Respir J. 2006;27(1):12-19. doi:10.1183/ 09031936.06.00008005

83. Wang JH, Lee SH, Kwon HJ, Jang YJ. Clarithromycin inhibits rhinovirus-induced bacterial adhesions to nasal epithelial cells. Laryngoscope. 2010;120(1):193-199. doi:10.1002/lary.20670

84. Abisheganaden JA, Avila PC, Kishiyama JL, et al. Effect of clarithromycin on experimental rhinovirus-16 colds: a randomized, double-blind, controlled trial. Am J Med. 2000;108(6):453-459. doi:10.1016/S0002-9343(00)00329-6

85. Suzuki T, Yamaya M, Sekizawa K, et al. Erythromycin inhibits rhinovirus infection in cultured human tracheal epithelial cells. Am J Respir Crit Care Med. 2002;165(8):1113-1118. doi:10.1164/ajrccm.165.8.2103094

86. Inoue D, Kubo H, Sasaki T, et al. Erythromycin attenuates MUC5AC synthesis and secretion in cultured human tracheal cells infected with RV14. Respirology. 2008;13(2):215-220. doi:10.1111/j.1440-1843.2007.01227.x

87. Yamaya M, Nishimura H, Hatachi Y, et al. Levofloxacin inhibits rhinovirus infection in primary cultures of human tracheal epithelial cells. Antimicrob Agents Chemother. 2012;56(8):4052-4061. doi:10.1128/AAC.00259-12

88. Acornley JE, Bessell CJ, Bynoe ML, Godtfredsen WO, Knoyle JM. Antiviral activity of sodium fusidate and related compounds. $B r J$ Pharmacol Chemother. 1967;31(2):210-220. doi:10.1111/j.1476-5381.1967.tb01992.x

89. Ianevski A, Zusinaite E, Kuivanen S, et al. Novel activities of safe-in-human broad-spectrum antiviral agents. Antiviral Res. 2018;154:174-182. doi:10.1016/j.antiviral.2018.04.016

90. Liao Y-T, Wang S-M, Chen S-H. Anti-inflammatory and antiviral effects of minocycline in enterovirus 71 infections. Biomed Pharmacother. 2019;118:109271. doi:10.1016/j.biopha.2019.109271

91. Shim A, Song J-H, Kwon B-E, et al. Therapeutic and prophylactic activity of itraconazole against human rhinovirus infection in a murine model. Sci Rep. 2016;6(1):1-12. doi:10.1038/srep23110

92. Gao Q, Yuan S, Zhang C, et al. Discovery of itraconazole with broad-spectrum in vitro antienterovirus activity that targets nonstructural protein 3A. Antimicrob Agents Chemother. 2015;59(5):2654-2665. doi:10.1128/AAC.05108-14

93. Lee J-S, Choi H-J, Song J-H, Ko H-J, Yoon K, Seong J-M. Antiviral activity of itraconazole against echovirus 30 infection in vitro. Osong Public Health Res Perspect. 2017;8(5):318-324. doi:10.24171/j.phrp.2017.8.5.05

94. Rhoden E, Nix WA, Weldon WC, Selvarangan R. Antifungal azoles itraconazole and posaconazole exhibit potent in vitro antiviral activity against clinical isolates of parechovirus A3 (Picornaviridae). Antiviral Res. 2018;149:75-77. doi:10.1016/j.antiviral.2017.11.011 
95. Xu F, Zhao X, Hu S, et al. Amphotericin B inhibits enterovirus 71 replication by impeding viral entry. Sci Rep. 2016;6(1):1-9. doi:10.1038/ s41598-016-0001-8

96. Kim C, Kang H, Kim D-E, et al. Antiviral activity of micafungin against enterovirus 71. Virol J. 2016;13(1):1-9. doi:10.1186/s12985-0160557-8

97. Kronenberger P, Vrijsen R, Boeye A. Chloroquine induces empty capsid formation during poliovirus eclipse. J Virol. 1991;65(12):7008-7011. doi:10.1128/jvi.65.12.7008-7011.1991

98. Lin HY, Yang YT, Yu SL, et al. Caveolar endocytosis is required for human PSGL-1-mediated enterovirus 71 infection. $J$ Virol. $2013 ; 87$ (16):9064-9076. doi:10.1128/JVI.00573-13

99. Tan YW, Yam WK, Sun J, Chu JJH. An evaluation of chloroquine as a broad-acting antiviral against hand, foot and mouth disease. Antiviral Res. 2018;149:143-149. doi:10.1016/j.antiviral.2017.11.017

100. Zink MC, Uhrlaub J, DeWitt J, et al. Neuroprotective and anti-human immunodeficiency virus activity of minocycline. JAMA. 2005;293 (16):2003-2011. doi:10.1001/jama.293.16.2003

101. Ratai EM, Bombardier JP, Joo CG, et al. Proton magnetic resonance spectroscopy reveals neuroprotection by oral minocycline in a nonhuman primate model of accelerated NeuroAIDS. PLoS One. 2010;5(5):e10523. doi:10.1371/journal.pone.0010523

102. Meulendyke KA, Pletnikov MV, Engle EL, Tarwater PM, Graham DR, Zink MC. Early minocycline treatment prevents a decrease in striatal dopamine in an SIV model of HIV-associated neurological disease. J Neuroimmune Pharmacol. 2011;7(2):454-464. doi:10.1007/s11481-0119332-1

103. Szeto GL, Brice AK, Yang HC, Barber SA, Siliciano RF, Clements JE. Minocycline attenuates HIV infection and reactivation by suppressing cellular activation in human CD4+ T cells. $J$ Infect Dis. 2010;201(8):1132-1140. doi:10.1086/651277

104. Singh M, Singh P, Vaira D, Amand M, Rahmouni S, Moutschen M. Minocycline attenuates HIV-1 infection and suppresses chronic immune activation in humanized NOD/LtsZ-scidIL-2Rgamma(null) mice. Immunology. 2014;142(4):562-572. doi:10.1111/imm.12246

105. Lemaître M, Guétard D, Hénin Y, Montagnier L, Zerial A. Protective activity of tetracycline analogs against the cytopathic effect of the human immunodeficiency viruses in CEM cells. Res Virol. 1990;141(1):5-16. doi:10.1016/0923-2516(90)90052-K

106. Wondrak EM, Löwer J, Kurth R. Inhibition of HIV-1 RNA-dependent DNA polymerase and cellular DNA polymerases $\alpha$, $\beta$ and $\gamma$ by phosphonoformic acid and other drugs. J Antimicrob Chemother. 1988;21(2):151-161. doi:10.1093/jac/21.2.151

107. Sturtz FG. Antimurine retroviral effect of doxycycline. Methods Find Exp Clin Pharmacol. 1998;20(8):643-648. doi:10.1358/ mf.1998.20.8.487489

108. Zapp ML, Stern S, Green MR. Small molecules that selectively block RNA binding of HIV-1 rev protein inhibit rev function and viral production. Cell. 1993;74(6):969-978. doi:10.1016/0092-8674(93)90720-B

109. Mei H-Y, Galan AA, Halim NS, et al. Inhibition of an HIV-1 Tat-derived peptide binding to TAR RNA by aminoglycoside antibiotics. Bioorg Med Chem Lett. 1995;5(22):2755-2760. doi:10.1016/0960-894X(95)00467-8

110. Wang S, Huber PW, Cui M, Czarnik AW, Mei H-Y. Binding of neomycin to the TAR element of HIV-1 RNA induces dissociation of tat protein by an allosteric mechanism. Biochemistry. 1998;37(16):5549-5557. doi:10.1021/bi972808a

111. Litovchick A, Lapidot A, Eisenstein M, Kalinkovich A, Borkow G. Neomycin B-arginine conjugate, a novel HIV-1 Tat antagonist: synthesis and anti-HIV activities. Biochemistry. 2001;40(51):15612-15623. doi:10.1021/bi0108655

112. Nozaki-Renard J, Iino T, Sato Y, Marumoto Y, Ohta G, Furusawa M. Fluoroquinolones protect the human lymphocyte CEM cell line from HIV1-mediated cytotoxicity. Cell Struct Funct. 1990;15(5):295-299. doi:10.1247/csf.15.295

113. Faber V, Newell A, Dalgleish AG, Malkovsky M. Inhibition of HIV replication in vitro by fusidic acid. Lancet. 1987;330(8563):827-828. doi:10.1016/S0140-6736(87)91016-6

114. Famularo G, Simone CD, Tzantzoglou S, Trinchieri V, Moretti S, Tonietti G. In vivo and in vitro efficacy of fusidic acid in HIV infection. Ann N Y Acad Sci. 1993;685(1 Immunomodulat):341-343. doi:10.1111/j.1749-6632.1993.tb35885.x

115. Balzarini J, Naesens L, Herdewijn P, et al. Marked in vivo antiretrovirus activity of 9-(2-phosphonylmethoxyethyl)adenine, a selective antihuman immunodeficiency virus agent. Proc Natl Acad Sci. 1989;86(1):332-336. doi:10.1073/pnas.86.1.332

116. Bourinbaiar AS, Lee-Huang S. Comparative in vitro study of contraceptive agents with anti-HIV activity: gramicidin, nonoxynol-9, and gossypol. Contraception. 1994;49(2):131-137. doi:10.1016/0010-7824(94)90088-4

117. Bourinbaiar AS, Krasinski K, Borkowsky W. Anti-HIV effect of gramicidin in vitro: potential for spermicide use. Life Sci. 1994;54(1):PL5PL9. doi:10.1016/0024-3205(94)00579-6

118. Mizrachi Y, Lev M, Harish Z, Sundaram SK, Rubinstein A. L-cycloserine, an inhibitor of sphingolipid biosynthesis, inhibits HIV-1 cytopathic effects, replication, and infectivity. J Acquir Immune Deficiency Syndr Human Retrovirol. 1996;11(2):137-141. doi:10.1097/00042560199602010-00004

119. Tsai WP, Nara PL, Kung HF, Oroszlan S. Inhibition of human immunodeficiency virus infectivity by chloroquine. AIDS Res Hum Retroviruses. 1990;6(4):481-489. doi:10.1089/aid.1990.6.481

120. Boelaert JR, Sperber K, Piette J. Chloroquine exerts an additive in vitro anti-HIV type 1 effect when associated with didanosine and hydroxyurea. AIDS Res Hum Retroviruses. 1999;15(14):1241-1247. doi:10.1089/088922299310133

121. Fesen MR, Kohn KW, Leteurtre F, Pommier Y. Inhibitors of human immunodeficiency virus integrase. Proc Natl Acad Sci. 1993;90(6):23992403. doi:10.1073/pnas.90.6.2399

122. Savarino A, Gennero L, Chen HC, et al. Anti-HIV effects of chloroquine: mechanisms of inhibition and spectrum of activity. AIDS. 2001;15 (17):2221-2229. doi:10.1097/00002030-200111230-00002

123. Neely M, Kalyesubula I, Bagenda D, Myers C, Olness K. Effect of chloroquine on human immunodeficiency virus (HIV) vertical transmission. Afr Health Sci. 2003;3(2):61-67.

124. Naarding MA, Baan E, Pollakis G, Paxton WA. Effect of chloroquine on reducing HIV-1 replication in vitro and the DC-SIGN mediated transfer of virus to CD4+ T-lymphocytes. Retrovirology. 2007;4:6. doi:10.1186/1742-4690-4-6

125. Sperber K, Louie M, Kraus T, et al. Hydroxychloroquine treatment of patients with human immunodeficiency virus type 1. Clin Ther. 1995;17 (4):622-636. doi:10.1016/0149-2918(95)80039-5

126. Sperber K, Kalb TH, Stecher VJ, Banerjee R, Mayer L. Inhibition of human immunodeficiency virus type 1 replication by hydroxychloroquine in T cells and monocytes. AIDS Res Hum Retroviruses. 1993;9(1):91-98. doi:10.1089/aid.1993.9.91 
127. Sperber K, Chiang G, Chen H, et al. Comparison of hydroxychloroquine with zidovudine in asymptomatic patients infected with human immunodeficiency virus type 1. Clin Ther. 1997;19(5):913-923. doi:10.1016/S0149-2918(97)80045-8

128. Chiang G, Sassaroli M, Louie M, Chen H, Stecher VJ, Sperber K. Inhibition of HIV-1 replication by hydroxychloroquine: mechanism of action and comparison with zidovudine. Clin Ther. 1996;18(6):1080-1092. doi:10.1016/S0149-2918(96)80063-4

129. Oguariri RM, Adelsberger JW, Baseler MW, Imamichi T. Evaluation of the effect of pyrimethamine, an antimalarial drug, on HIV-1 replication. Virus Res. 2010;153(2):269-276. doi:10.1016/j.virusres.2010.08.018

130. Stoddart CA, Rothan HA, Bahrani H, et al. A combination of doxycycline and ribavirin alleviated chikungunya infection. PLoS One. 2015;10 (5):e0126360. doi:10.1371/journal.pone.0126360

131. Irani DN, Prow NA. Neuroprotective interventions targeting detrimental host immune responses protect mice from fatal alphavirus encephalitis. J Neuropathol Exp Neurol. 2007;66(6):533-544. doi:10.1097/01.jnen.0000263867.46070.e2

132. Ho Y-J, Liu F-C, Yeh C-T, et al. Micafungin is a novel antiviral agent of chikungunya virus through multiple mechanisms. Antiviral Res. 2018;159:134-142. doi:10.1016/j.antiviral.2018.10.005

133. Umino Y, Tashiro M. Inhibition of rubella virus growth by Fungizone. Vaccine. 2001;19(11-12):1369-1372. doi:10.1016/S0264-410X(00) $00371-6$

134. Khan M, Santhosh SR, Tiwari M, Lakshmana Rao PV, Parida M. Assessment of in vitro prophylactic and therapeutic efficacy of chloroquine against Chikungunya virus in Vero cells. J Med Virol. 2010;82(5):817-824. doi:10.1002/jmv.21663

135. Roques P, Thiberville S-D, Dupuis-Maguiraga L, et al. Paradoxical effect of chloroquine treatment in enhancing chikungunya virus infection. Viruses. 2018;10(5):268. doi:10.3390/v10050268

136. Umbro I, Anzivino E, Tinti F, et al. Possible antiviral effect of ciprofloxacin treatment on polyomavirus BK replication and analysis of noncoding control region sequences. Virol J. 2013;10:274. doi:10.1186/1743-422X-10-274

137. Leung AY, Chan MT, Yuen KY, et al. Ciprofloxacin decreased polyoma BK virus load in patients who underwent allogeneic hematopoietic stem cell transplantation. Clin Infect Dis. 2005;40(4):528-537. doi:10.1086/427291

138. Koukoulaki M, Apostolou T, Hadjiconstantinou V, Drakopoulos S. Impact of prophylactic administration of ciprofloxacin on BK polyoma virus replication. Transpl Infect Dis. 2008;10(6):449-451. doi:10.1111/j.1399-3062.2008.00334.x

139. Gabardi S, Waikar SS, Martin S, et al. Evaluation of fluoroquinolones for the prevention of BK viremia after renal transplantation. Clin $J$ Am Soc Nephrol. 2010;5(7):1298-1304. doi:10.2215/CJN.08261109

140. Jeffers-Francis LK, Burger-Calderon R, Webster-Cyriaque J. Effect of leflunomide, cidofovir and ciprofloxacin on replication of BKPyV in a salivary gland in vitro culture system. Antiviral Res. 2015;118:46-55. doi:10.1016/j.antiviral.2015.02.002

141. Pasternak J, Rajtar B, Stec A, Polz-Dacewicz M. Antiviral activity of ciprofloxacin on BK virus in an in vitro culture - pilot study. J Pre Clin Clin Res. 2017;11(2):116-119. doi:10.26444/jpccr/78587

142. Randhawa PS. Anti-BK virus activity of ciprofloxacin and related antibiotics. Clin Infect Dis. 2005;41(9):1366-1367. doi:10.1086/497080

143. Ali SH, Chandraker A, DeCaprio JA. Inhibition of Simian virus 40 large $\mathrm{T}$ antigen helicase activity by fluoroquinolones. Antivir Ther. 2007;12 (1): $1-6$.

144. Toptas T, Kaygusuz-Atagunduz I, Kani HT, Adiguzel C, Firatli-Tuglular T. Levofloxacin for the treatment of severe refractory BK virusassociated hemorrhagic cystitis in hematopoietic stem cell transplantation recipients: a report of three cases. Oncol Lett. 2014;8(4):1775-1777. doi:10.3892/ol.2014.2381

145. Schaeffer EM. Re: levofloxacin for BK virus prophylaxis following kidney transplantation: a randomized clinical trial. J Urol. 2015;194 (2):410-411.

146. Sharma BN, Li R, Bernhoff E, Gutteberg TJ, Rinaldo CH. Fluoroquinolones inhibit human polyomavirus BK (BKV) replication in primary human kidney cells. Antiviral Res. 2011;92(1):115-123. doi:10.1016/j.antiviral.2011.07.012

147. Brickelmaier M, Lugovskoy A, Kartikeyan R, et al. Identification and characterization of mefloquine efficacy against JC virus in vitro. Antimicrob Agents Chemother. 2009;53(5):1840-1849. doi:10.1128/AAC.01614-08

148. D'Alessandro S, Scaccabarozzi D, Signorini L, et al. The use of antimalarial drugs against viral infection. Microorganisms. $2020 ; 8(1): 85$. doi:10.3390/microorganisms 8010085

149. Chan JF-W, Ma -MK-M, Chan GS-W, et al. Rapid reduction of viruria and stabilization of allograft function by fusidic acid in a renal transplant recipient with JC virus-associated nephropathy. Infection. 2015;43(5):577-581. doi:10.1007/s15010-015-0721-x

150. Ikeda S, Yazawa M, Nishimura C. Antiviral activity and inhibition of topoisomerase by ofloxacin, a new quinolone derivative. Antiviral Res. 1987;8(3):103-113. doi:10.1016/0166-3542(87)90064-7

151. Moss B, Katz E, Rosenblum EN. Vaccinia virus directed RNA and protein synthesis in the presence of rifampicin. Biochem Biophys Res Commun. 1969;36(5):858-865. doi:10.1016/0006-291X(69)90688-3

152. Subak-Sharpe JH, Timbury MC, Williams JF. Rifampicin inhibits the growth of some mammalian viruses. Nature. 1969;222(5191):341-345. doi:10.1038/222341a0

153. Tan KB, McAuslan BR. Effect of rifampicin on poxvirus protein synthesis. $J$ Virol. 1970;6(3):326-332. doi:10.1128/jvi.6.3.326-332.1970

154. Ben-Ishai Z, Heller E, Goldblum N, Becker Y. Rifampicin and poxvirus replication. Nature. 1969;224(5214):29-32. doi:10.1038/224029a0

155. Moss B, Rosenblum EN, Katz E, Grimley PM. Rifampicin: a specific inhibitor of vaccinia virus assembly. Nature. 1969;224(5226):1280-1284. doi:10.1038/2241280a0

156. Nagayama A, Pogo BGT, Dales S. Biogenesis of vaccinia: separation of early stages from maturation by means of rifampicin. Virology. 1970;40 (4):1039-1051. doi:10.1016/0042-6822(70)90150-9

157. Pogo BGT. Biogenesis of vaccinia: effect of rifampicin on transcription. Virology. 1971;44(3):576-581. doi:10.1016/0042-6822(71)90371-0

158. Garriga D, Headey S, Accurso C, Gunzburg M, Scanlon M, Coulibaly F. Structural basis for the inhibition of poxvirus assembly by the antibiotic rifampicin. Proc Natl Acad Sci. 2018;115(33):8424-8429. doi:10.1073/pnas.1810398115

159. Toolan HW, Ledinko N. Effect of rifampicin on the development of tumours induced by adenovirus in male hamsters. Nat New Biol. 1972;237 (76):200-202. doi:10.1038/newbio237200a0

160. Sun P, Yu F, Lu J, et al. In vivo effects of neomycin sulfate on non-specific immunity, oxidative damage and replication of cyprinid herpesvirus 2 in crucian carp (Carassius auratus gibelio). Aquac Fish. 2019;4(2):67-73. doi:10.1016/j.aaf.2018.09.003 
161. Asada M, Yoshida M, Suzuki T, et al. Macrolide antibiotics inhibit respiratory syncytial virus infection in human airway epithelial cells. Antiviral Res. 2009;83(2):191-200. doi:10.1016/j.antiviral.2009.05.003

162. Bawage SS, Tiwari PM, Pillai S, Dennis VA, Singh SR. Antibiotic minocycline prevents respiratory syncytial virus infection. Viruses. 2019;11 (8):739. doi:10.3390/v11080739

163. Richardson-Burns SM, Tyler KL. Minocycline delays disease onset and mortality in reovirus encephalitis. Exp Neurol. 2005;192(2):331-339. doi:10.1016/j.expneurol.2004.11.015

164. Wu ZC, Wang X, Wei JC, et al. Antiviral activity of doxycycline against vesicular stomatitis virus in vitro. FEMS Microbiol Lett. 2015;362(22): fnv195. doi:10.1093/femsle/fnv195

165. Sharifi A, Amanlou A, Moosavi-Movahedi F, Golestanian S, Amanlou M. Tetracyclines as a potential antiviral therapy against Crimean Congo hemorrhagic fever virus: docking and molecular dynamic studies. Comput Biol Chem. 2017;70:1-6. doi:10.1016/j.compbiolchem.2017.06.003

166. Kvistgaard AS, Pallesen LT, Arias CF, et al. Inhibitory effects of human and bovine milk constituents on rotavirus infections. $J$ Dairy Sci. 2004;87(12):4088-4096. doi:10.3168/jds.S0022-0302(04)73551-1

167. Zhou N, Pan T, Zhang J, et al. Glycopeptide antibiotics potently inhibit cathepsin L in the late endosome/lysosome and block the entry of Ebola virus, middle east respiratory syndrome coronavirus (MERS-CoV), and severe acute respiratory syndrome coronavirus (SARS-CoV). $J$ Biol Chem. 2016;291(17):9218-9232. doi:10.1074/jbc.M116.716100

168. Wang Y, Cui R, Li G, et al. Teicoplanin inhibits Ebola pseudovirus infection in cell culture. Antiviral Res. 2016;125:1-7. doi:10.1016/j. antiviral.2015.11.003

169. Sun W, He S, Martínez-Romero C, et al. Synergistic drug combination effectively blocks Ebola virus infection. Antiviral Res. 2017;137:165172. doi:10.1016/j.antiviral.2016.11.017

170. Burdick JR, Durand DP. Primaquine diphosphate: inhibition of Newcastle disease virus replication. Antimicrob Agents Chemother. 1974;6 (4):460-464. doi:10.1128/AAC.6.4.460

171. Rogée S, Larrous F, Jochmans D, Ben-Khalifa Y, Neyts J, Bourhy H. Pyrimethamine inhibits rabies virus replication in vitro. Antiviral Res. 2019;161:1-9. doi:10.1016/j.antiviral.2018.10.016

Journal of Experimental Pharmacology

Dovepress

\section{Publish your work in this journal}

The Journal of Experimental Pharmacology is an international, peer-reviewed, open access journal publishing original research, reports, reviews and commentaries on all areas of laboratory and experimental pharmacology. The manuscript management system is completely online and includes a very quick and fair peer-review system. Visit http://www.dovepress.com/testimonials.php to read real quotes from published authors.

Submit your manuscript here: https://www.dovepress.com/journal-of-experimental-pharmacology-journal 